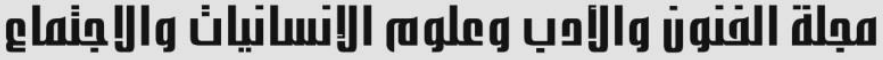

Journal of Arts, Literature, Humanities and Social Sciences

\section{آيات التحكيم عند مفسري الإباضيّة \\ (دراسة في الإسقاطات التاريخيّة والقبليّات الفكريّة)}

\author{
م.م. مشاري علاوي مشكور خليف البلدريّ

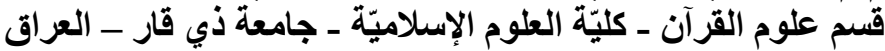 \\ الايميل: moshary798@gmail.com

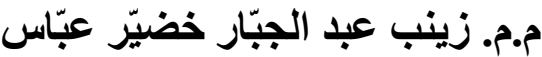

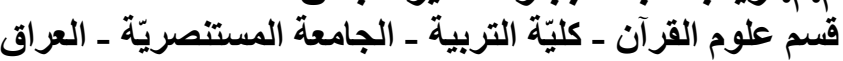 \\ zainab.alqutby@yahoo.com:الايميل
}

و احدة من الأسس التي قامت عليها فرقة الإباضيّة هي مسألة التحكيم، فمنذ هذه المسألة بدأت تتشكّل تللك الفرقة، ومن ثمَّ بدأت تتثكّل عقائدهم وفق هذه الحادثة في التاريخ الإسلاميّ، إذ كانت أقو الهم في مبحث الإمامة في مجال العقيدة يدور حول إسقاط تاريخ هذه المسألة على أقو الهم العقديّة. وحين اصطدم مفسّرو هذه الطائفة بالآيات التي تجيز التحكيمَ، و التي تدلُّ على جوازِهِ بل و عزيمته ـأخذوا بتأويلِ تلالكَ الآياتِ حنّى لا تصطدمَ مع ما يعتقدونَ، إذ أخذوا بليِّ أعناقِ النصوصِِ التي تبيح التحكيم في الخلاف، و التحكيم حتّى في اختلاف الزوجينِ حين النشوز. وقد أوّلوا نللكَّ الآيات وأسقطوا النتاريخ الذي يعتقدون، فكان البحث در اسةً لتلكِ الإسقاطات التاريخيّة و أثر ها في تغيير تفسير النصوص الظاهرة. 


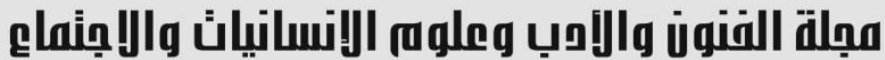

Journal of Arts, Literature, Humanities and Social Sciences

\section{Arbitration Verses for the Ibadi Interpreters}

\section{(A Study of historical projections and intellectual tribes)}

\author{
Mishary Allawi Mashkour Khalif Al-Badri \\ Department of Quranic Sciences - College of Islamic Sciences \\ Dhi Qar University - Iraq \\ Email: moshary798@gmail.com \\ Zainab Abdul Jabbar Khudair Abbas \\ Department of Quranic Sciences - College of Education \\ Al-Mustansiriya University - Iraq \\ Email: zainab.alqutby@yahoo.com
}

\begin{abstract}
One of the foundations on which the Ibadi sect was based is the issue of arbitration, since this issue began to form that division, and then their beliefs began to form according to this incident in Islamic history, as their statements in the topic of the Imamate in the field of belief were about projecting the history of this issue on their doctrinal sayings.

When the interpreters of this sect collided with the verses that permitted arbitration, which indicate its permissibility and even its intention - they interpreted those verses in order not to clash with what they believe, as they took on the necks of the texts that permitted arbitration in disagreement, and arbitration even in the difference of the spouses when disobedience. They have prioritized these verses and dropped the history they believe, so the research was a study of these historical projections and their effect on changing the interpretation of the apparent texts.
\end{abstract}

Keywords: Arbitration verses, Ibadi, interpreters of Ibadi, interpretation of the Qur'an. 


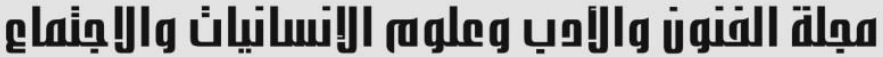

Journal of Arts, Literature, Humanities and Social Sciences

www.jalhss.com

\section{تمهيد: نشأة الخوارج والفرقة الإباضية وعقائدهم}

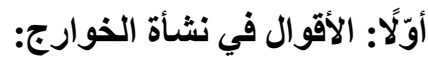

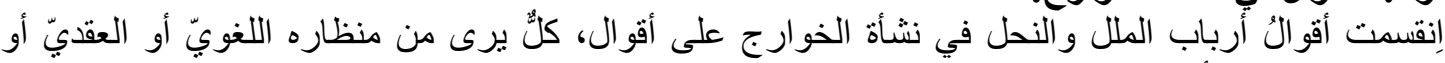

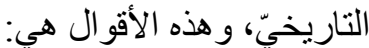

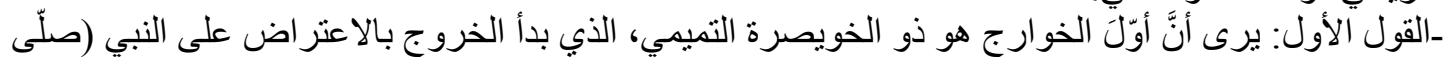

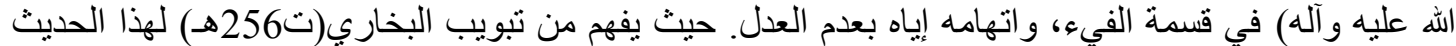

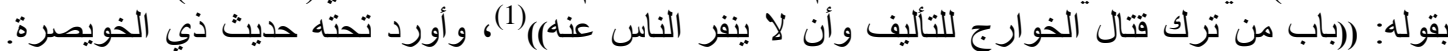

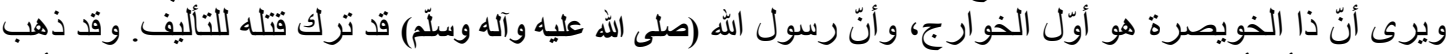

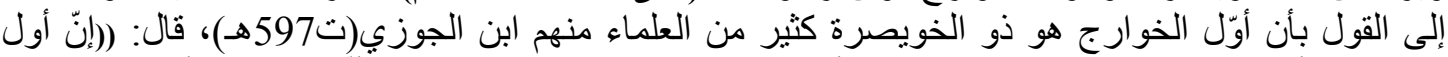

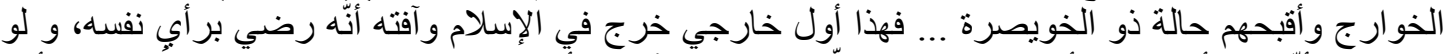

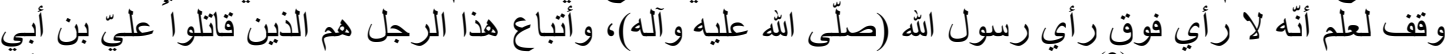

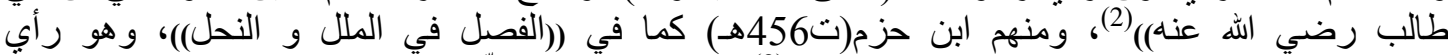

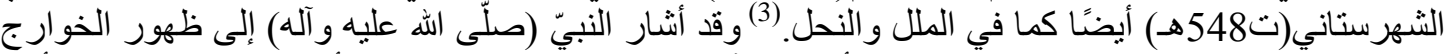

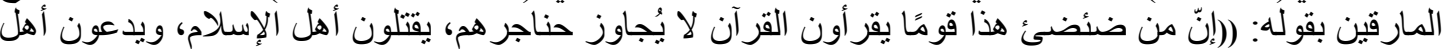

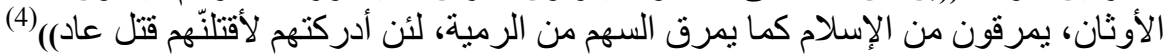

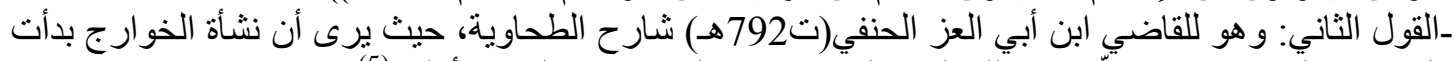

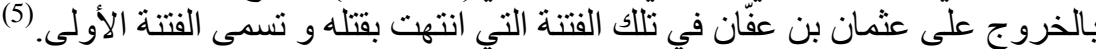

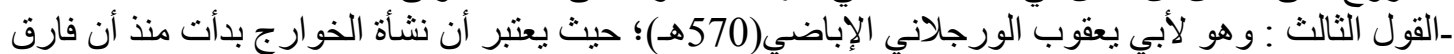

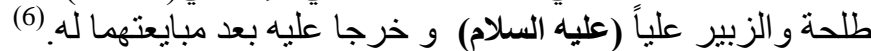

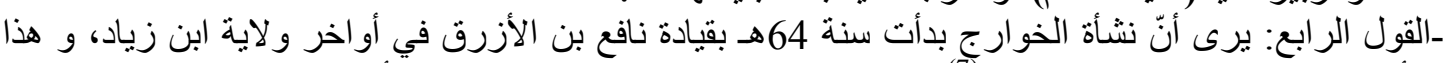

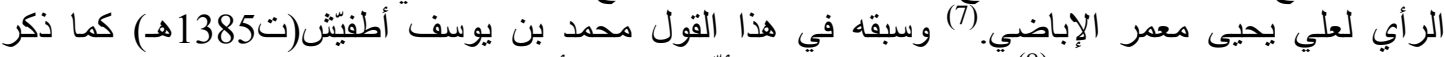

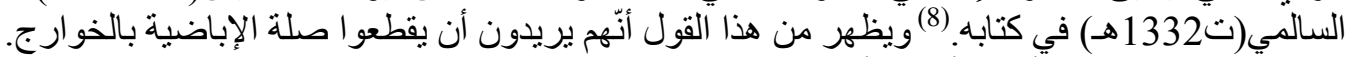

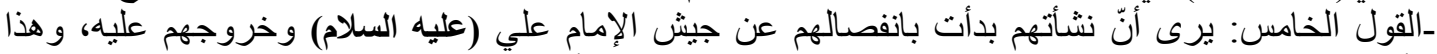
الر أي هو الذي عليه الكثرة الغالبة من العلماء إذ يعرّفون الخوارج بأنهم هم الذين خرجو الفيه على علي (عليه السلام)

هناك خلاف بين الأباضية حول فتح همزة أباض أو كسرها، فالأباضية في عُمان يفتحون الهمزة، وبذلك تصبح

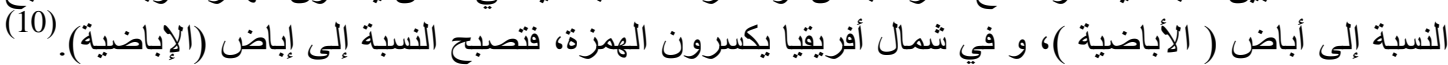

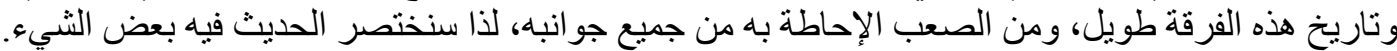

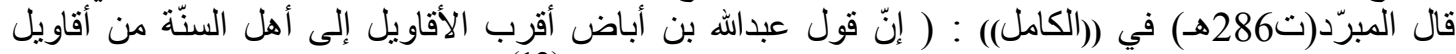

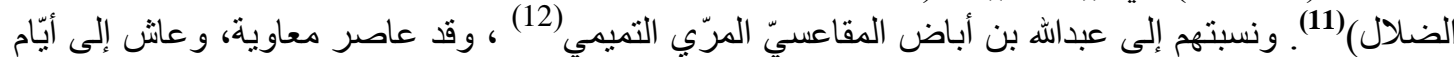

$$
\text { (2) (1) تلبيس إبليس، البخاري: 8/ 52-53 باب من ترك قتال الخوارج للتأليف وأن لا ينفر الناس عنه. }
$$

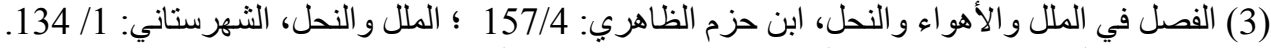

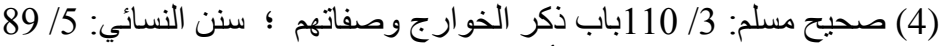

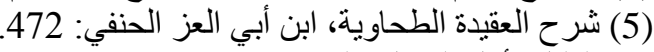

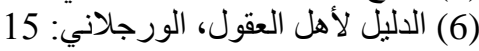

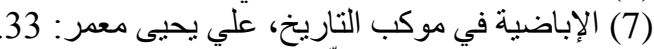

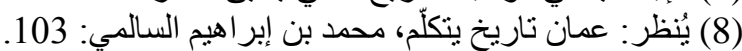

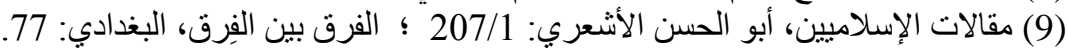
(10) يُنظر : العقود الفضيّة في أصول الإباضيّة، سالم بن حمد بن سليمان الحارثيّ: 121-122. 


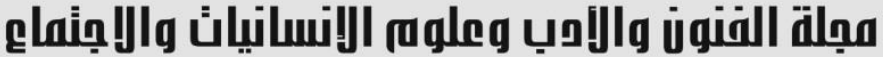

Journal of Arts, Literature, Humanities and Social Sciences www.jalhss.com

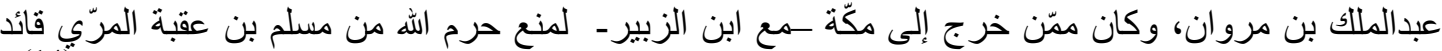

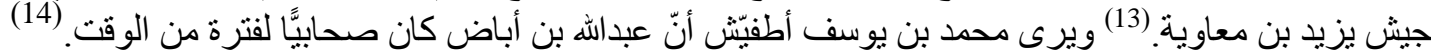

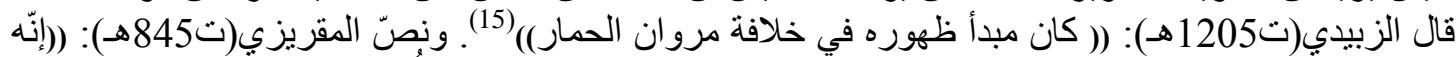

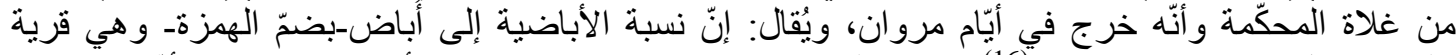

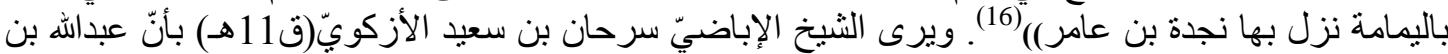

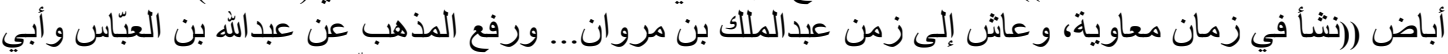

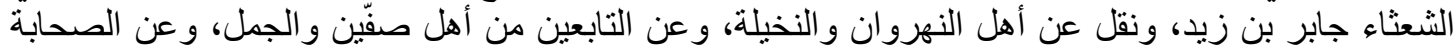

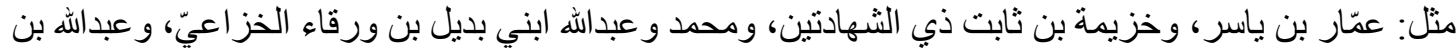

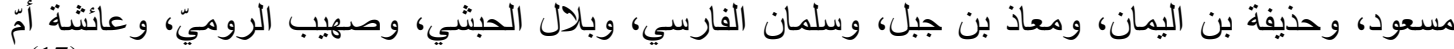
المؤمنين، و الخليفتين الرضيّين المرضيّين أبي بكر و عمر، و والمهاجرين والأنصار رضين وضي الله عنهم أجمعين)( (17).

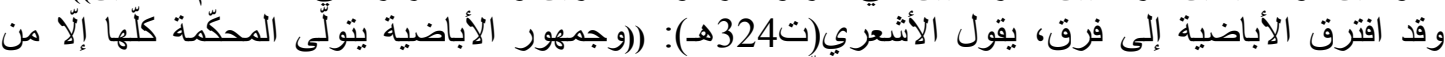

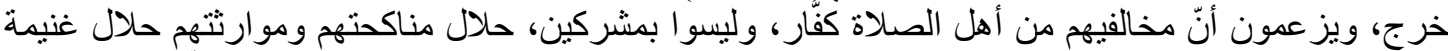

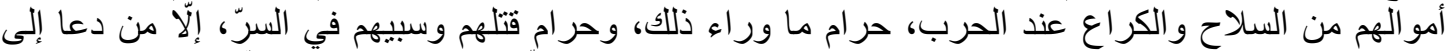

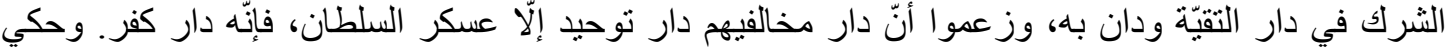

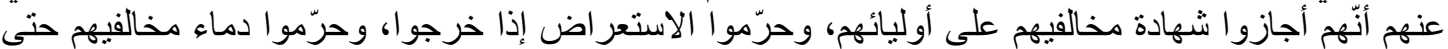

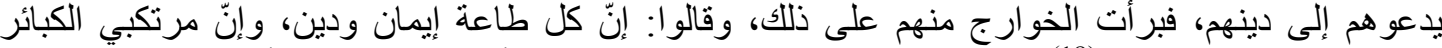

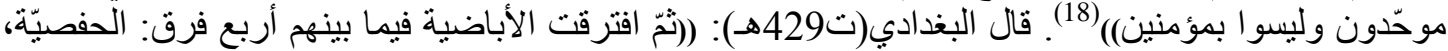

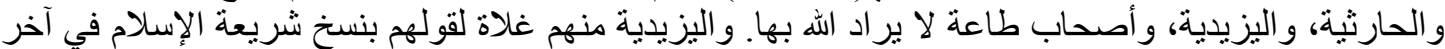

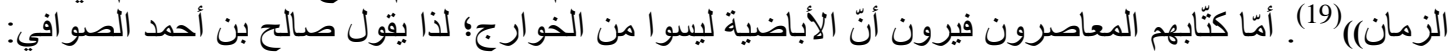

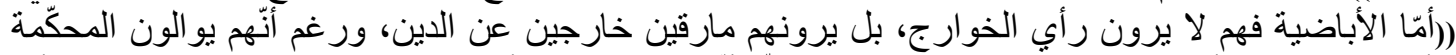

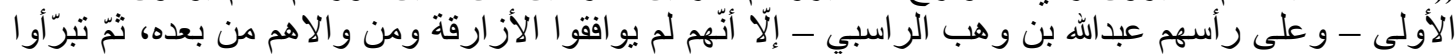

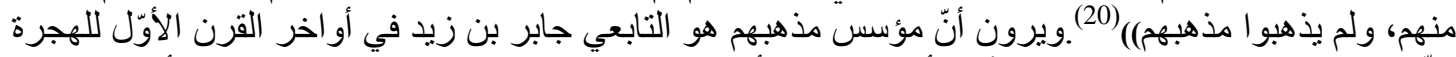

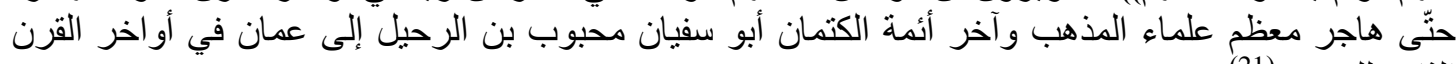

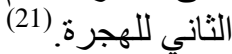

ويُطلقِ اسم (القَعَدة) على الإباضيّة، ويعود هذا الاسم إلى بو اكبر هم، وهم جماعة انثقّت بعد النهروان، وآثرت

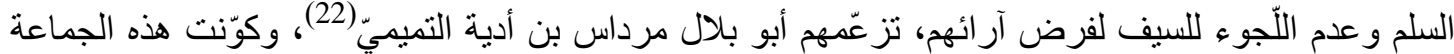

(11) الكامل في اللغة والأدب، أبو العبّاس المبرّد: 2 / 214.

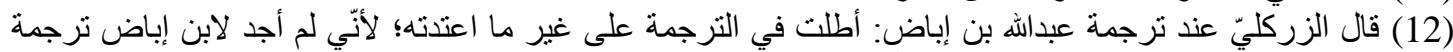

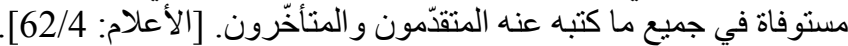

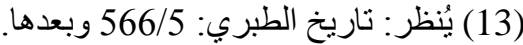

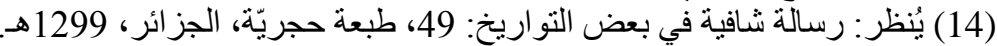

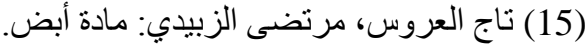

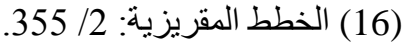

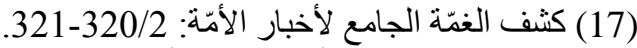

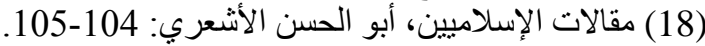

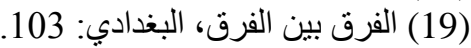
(20) الإمام جابر بن زيد العماني، صالح بن الخدي: أحمد الصو افي: 212.

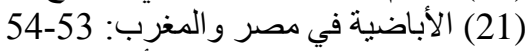

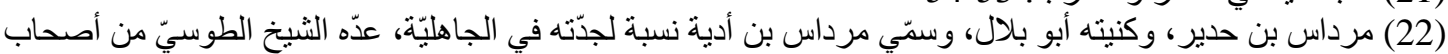

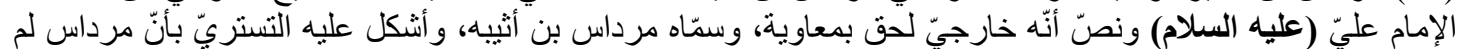

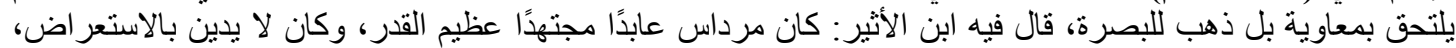

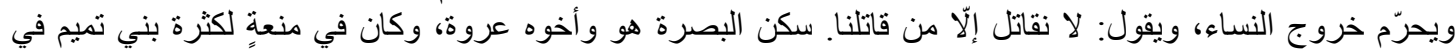




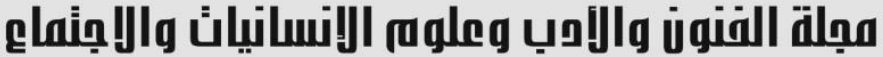

Journal of Arts, Literature, Humanities and Social Sciences www.jalhss.com

البذرة التي أنتجت الفرقة الإباضيّة، وقد أنكر الخوارج المتطرّفون قعود (أتباع مرداس) عن الخروج بالسيف،

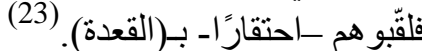

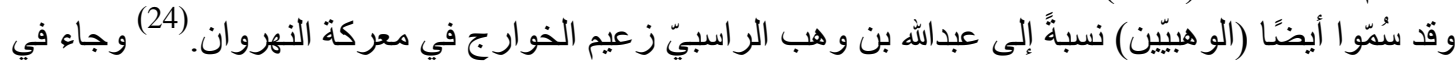

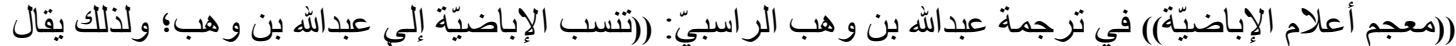

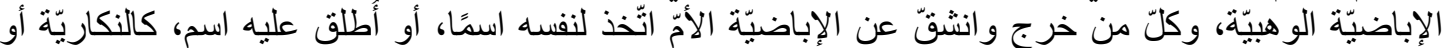

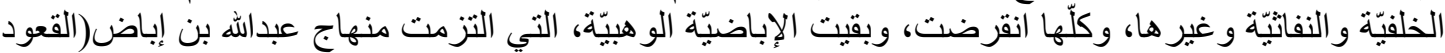

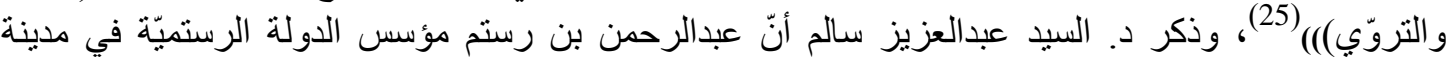

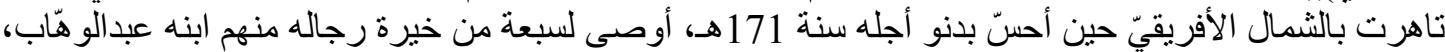

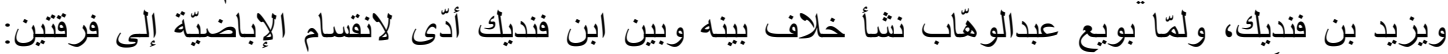

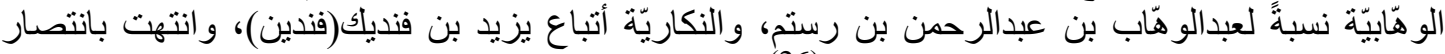

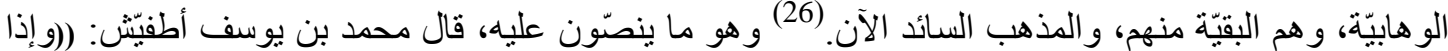

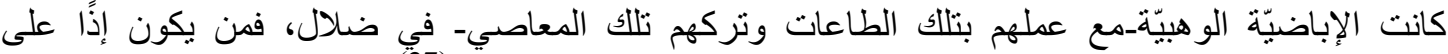

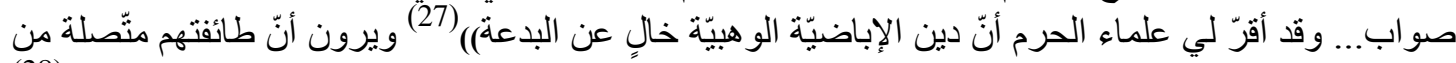
عبدالو هأب و أبيه عبدالرحمن عن أبي عبيدة مسلم عن جابر بن زيد عن ابن عبّاس وعائشة أمّ المؤمنين. (28)

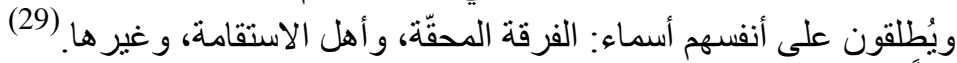
ثالثًا: عقائد الأباضية الثمانية الثمانية:

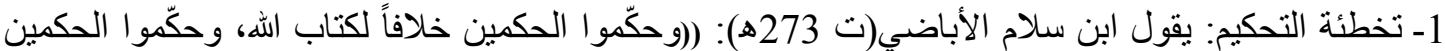

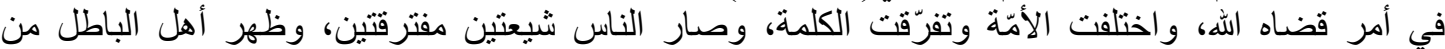

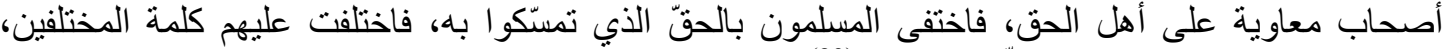
يقتلونهم على دين الله الحنيف و الملّة الصادقة فلة) (30).

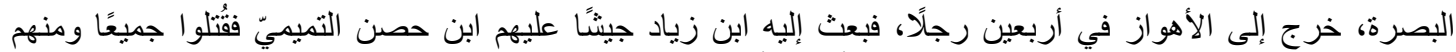

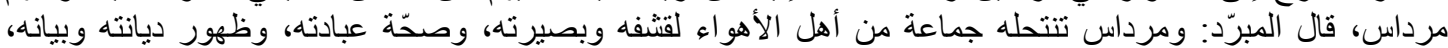

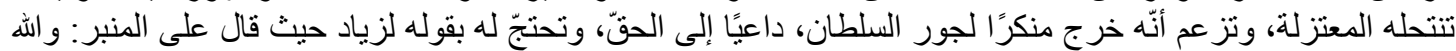

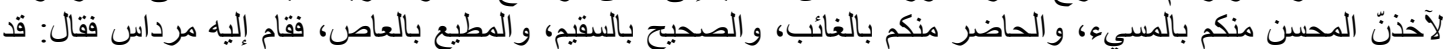

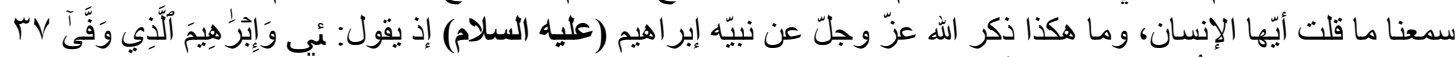

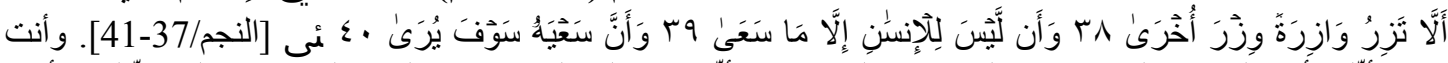

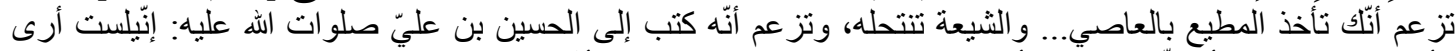

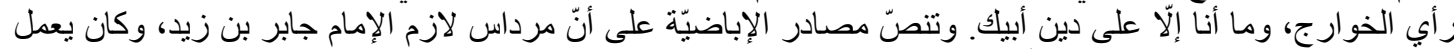

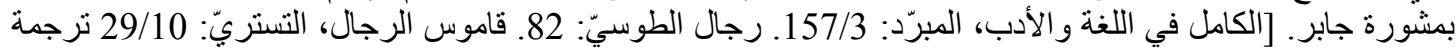

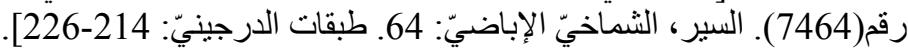

(23) يُنظر: طبقات الدرجينيّ، أبو العبّاس أحمد بن سعيد الدرجينيّ، تحقيق: إبرا اهيم طلّاّي: 214/2 وبعدها. ويُنظر : نشأة

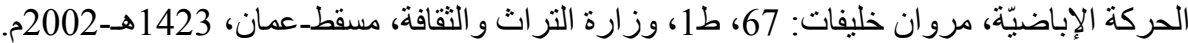

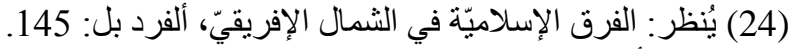
(25) معجم أعلام الإباضيّة: 293/1 : 29:

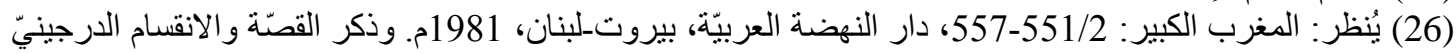
في الطبقات: 47/26 وبعدها.

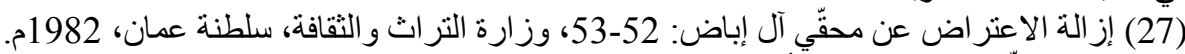

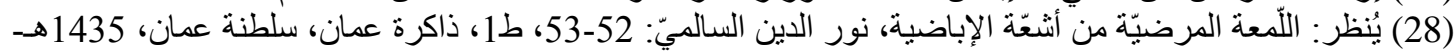




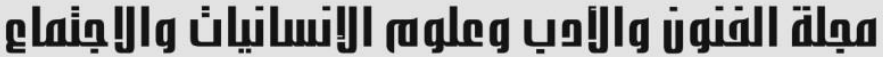

Journal of Arts, Literature, Humanities and Social Sciences www.jalhss.com

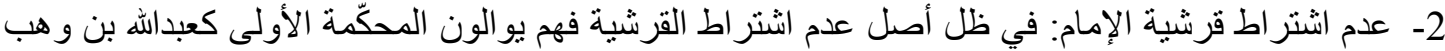

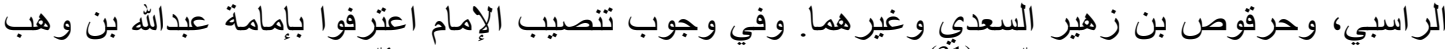

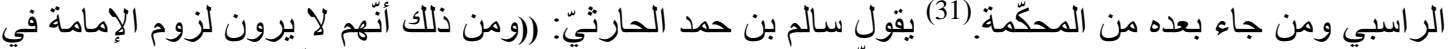

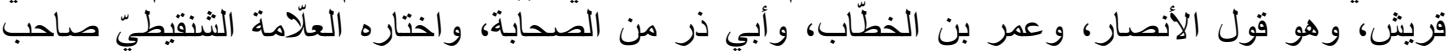

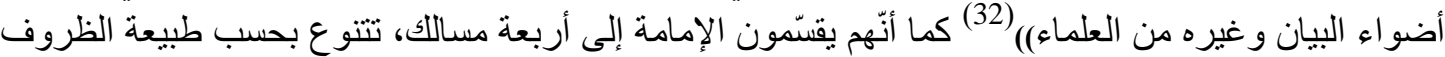

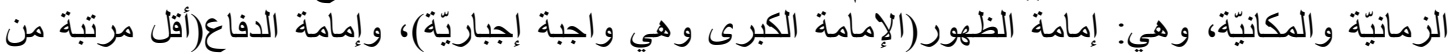

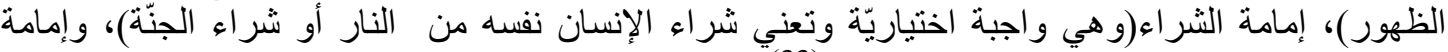

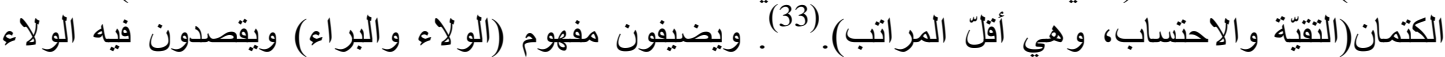

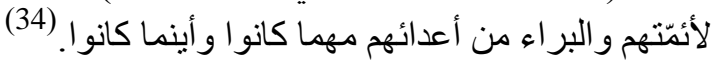

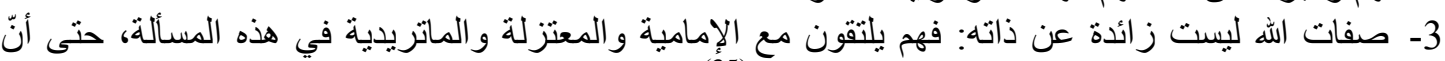

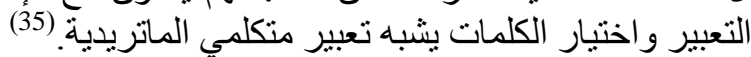
4- امتناع رؤية الله تعالى في الآخرة: وهم بهذا القول يوافقون الإمامية و المعتزلة، يقولئل يقول علي يحيى معمّر : (و المعتدلون من الأباضية لا يمنعون أن يكون معنى الرؤية هو كمال العلم به تعالى، ويمنعون الرؤية بالصورة الصايه

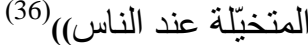
5- القرآن حادث غير قديم: وهم يو افقون الإماميّة و المعتزلة بهذا القول. وهذا القول يختلف فيه أباضية المغرب

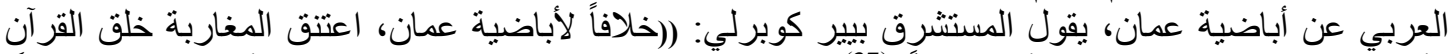

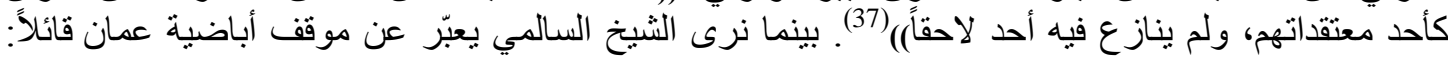

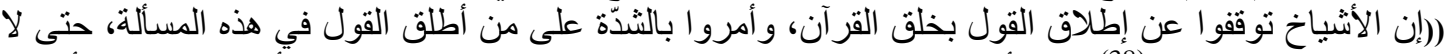

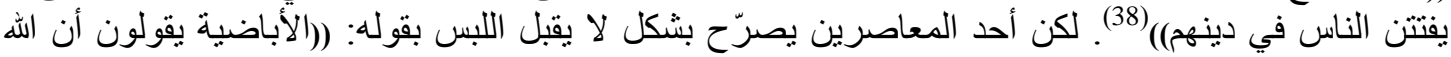

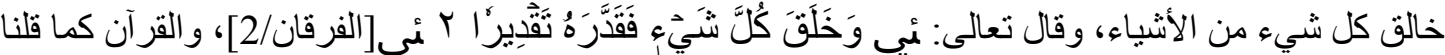

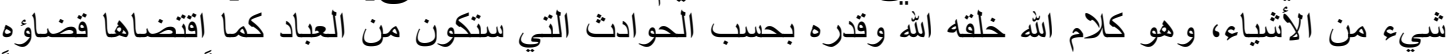

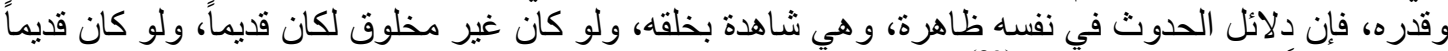

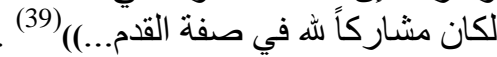

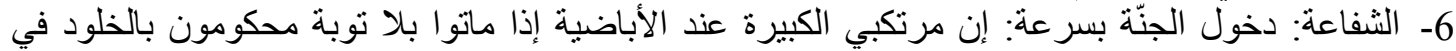

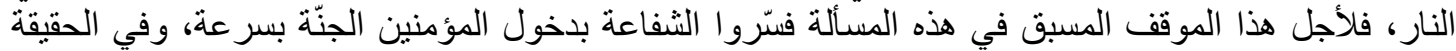
خصنّو ها بغير المذنبين من الأمة، و هذا التفسير يو افق ما عليه المعتزلة من أن الغاية من الثفاعة هو رفع الدرجة

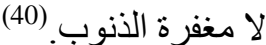
7- مرتكب الكبيرة كافر نعمة لا كافر ملّة: اتفق الخوارج حتى الأباضية أن ارتكاب الكبيرة موجب للكفر، لكن

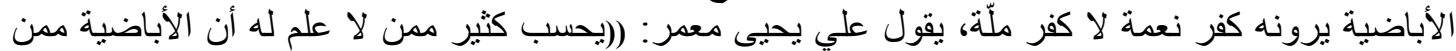

(31) ينظر بحوث في الملل و النحل، جعفر السبحاني: 279 المبنة 290.

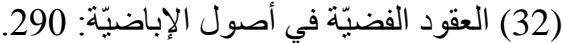

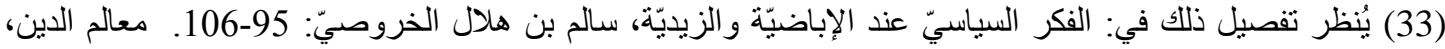

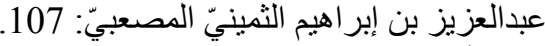
(35) يُنظر : معالم الدين، المصنعبيّ: 126. (35) الأباضية بين الفرق الإسلامية، علي يحيى معدر : 126 / 1295.

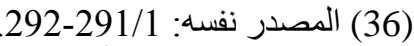
(37) مدخل إلى در اسة الأباضية و عقيدتها، بيير كوبرلي: 315.

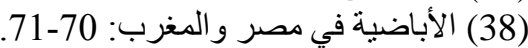




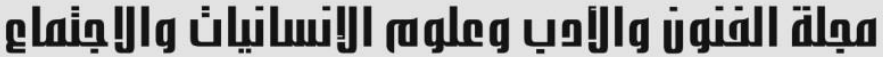
www.jalhss.com

يتفقون مع الخوارج في تكفير العصاة كفر شرك، ولا يعرفون أن الأباضية يطلقون كلمة الكفر على عصاة

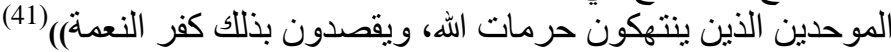

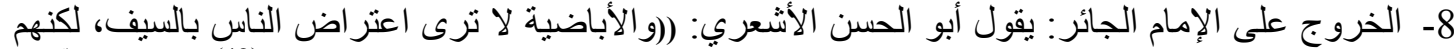

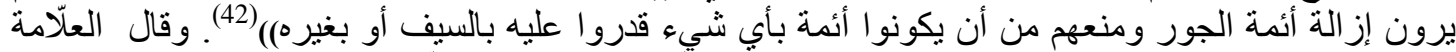

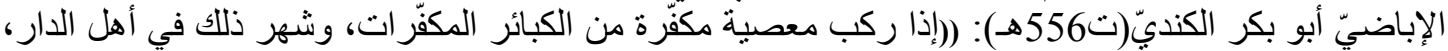

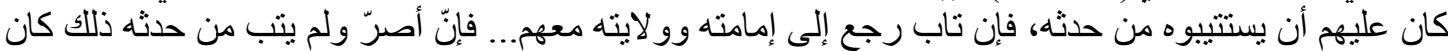

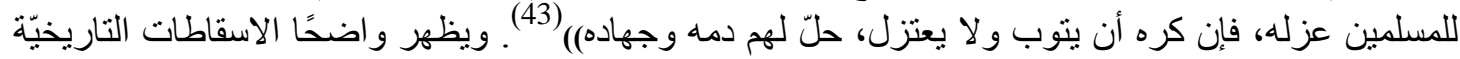

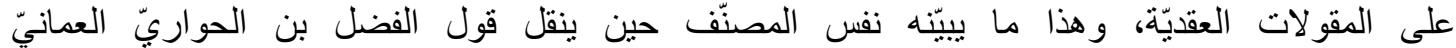

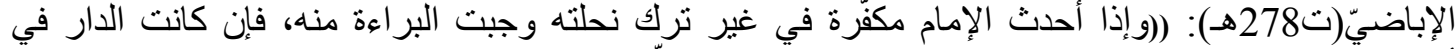

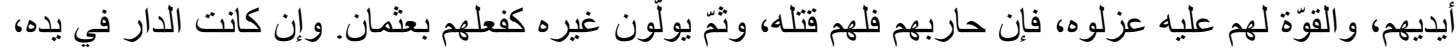

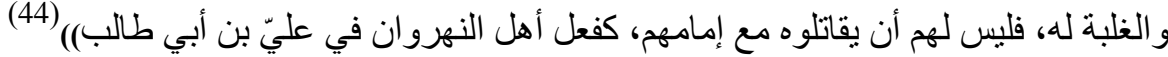

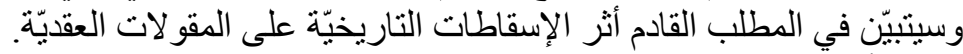

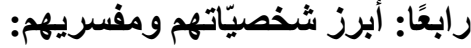

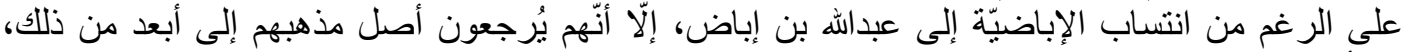

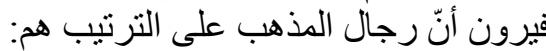

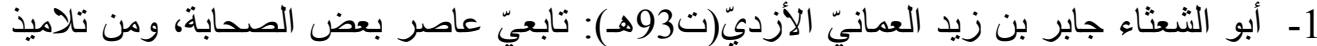

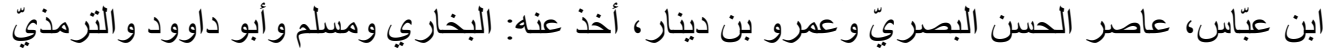

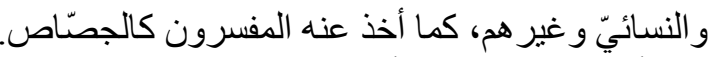

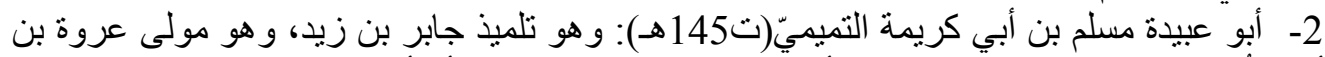

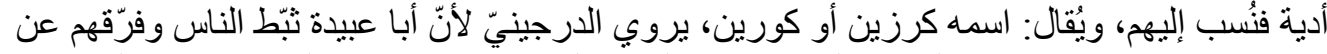

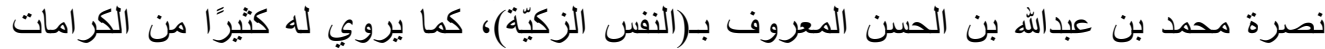

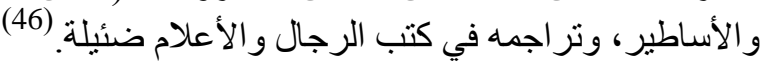

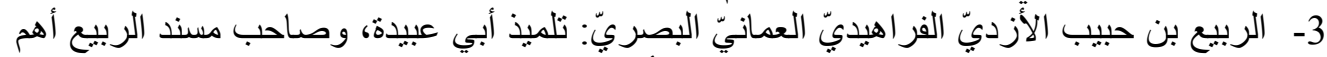

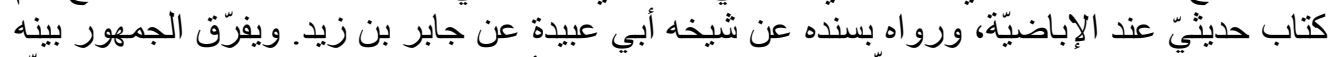

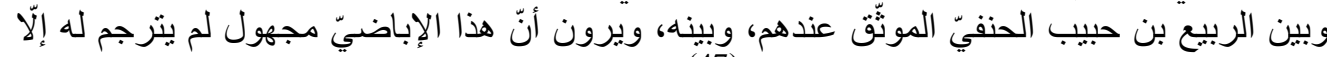

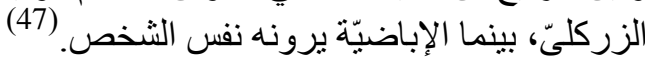

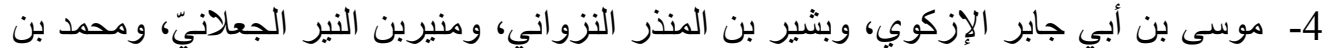

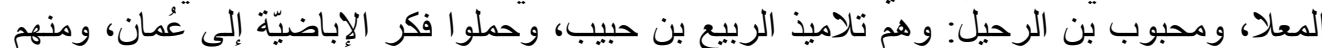

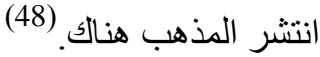
5- عبداله بن إباض: هلن وقد تقدمت ترجمته وله يُنسبون.

(41) الأباضية في موكب التاريخ، علي يحبى معمر: 89. (42) (43) مقالات الإسلاميين: 189.

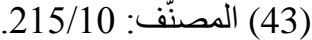
(44) (4) المصدر نفسه: 218/10. (45) سير أعلام النبلاء، الذهبيّ: 481/4-483 ترجمة رقم(184). إزالة الوعثاء عن أتباع أبي الثُشثاء، سالم بن حمود (السيابيّ: (4) 3. (46) أستوفى ترجمته وحياته: سعد بن عبداله بن عبدالعزيز الحميد، في بحثه الموسوم بـ(أبو عبيدة مسلم بن أبي كريمة

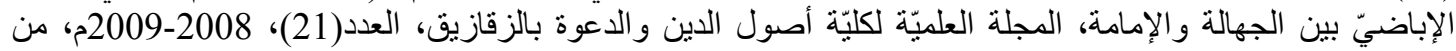

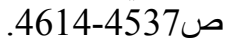
(47) يُنظر : سلسلة الأحاديث الضعيفة والموضو عة و وأثرها السيّه على الأمَّة، ناصر الدين الألباني: 108/13. الأعلام، 


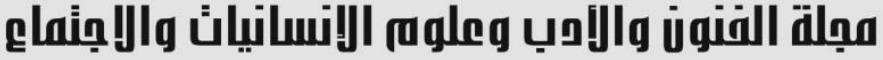
www.jalhss.com

$$
\text { أهم تفاسير هم: أ- أمفقودة: }
$$

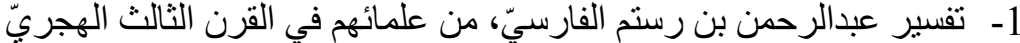

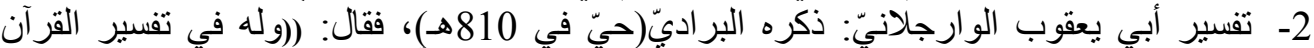

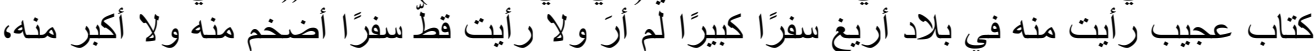

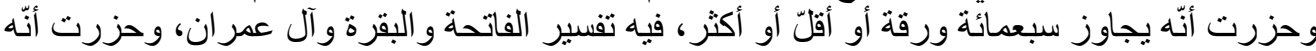

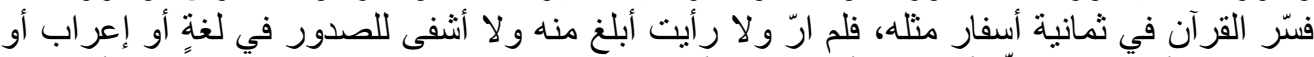

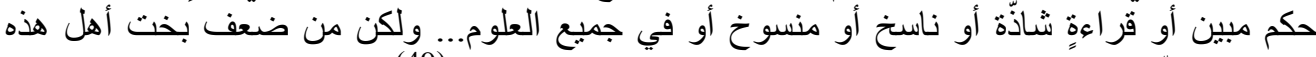

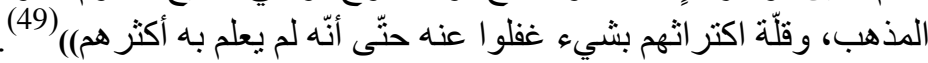
بـ- التفاسير الموجودة: 1- تفسير كتاب الله العزيز لهود بن محكم الهواريّ: وهو تفسير مطبوع بأربعة أجز اء حقّه بالحاج بن سعبد شريفي. 2- في رحآب القرآن (مختصر تفسير بيوض): و المطبوع منه ستة أجزاء، وبرواية ورش عن نافع،

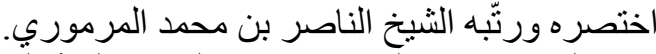

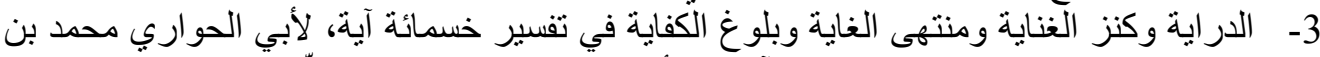
الحواري العماني الإباضي: وهو تفسير لآيات الأحكام، مطبوع بجزئين، حقّه: محمد محمد زناتي لإئي عبدالرحمن. 4- هميان الز اد إلى دار المعاد، محمد بن يوسف أطفيّش: وهو أكبر تفسير عنده، المطبوع منه أربعة

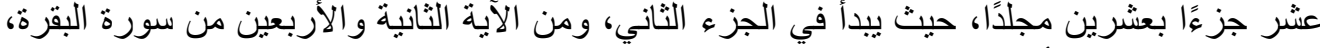
و هو تفسير صنبّ فيه أطفيّش كلّ عقائده. 5- تيسير التفسير ، محمد بن يوسف أطفيّش: وهو هو تفسير اختصر فيه تفسيره السابق.

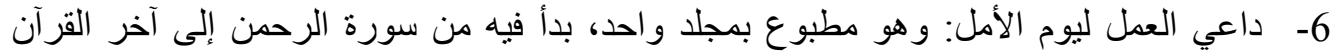
الكريم، ولم يتمّه صاحبه. 7- جوا اهر التفسير ، لأحمد بن حمد الخليليّ(مفتي عُمان): وهو تفسير مطبوع ومسموع ومرئيّ، إذ هو

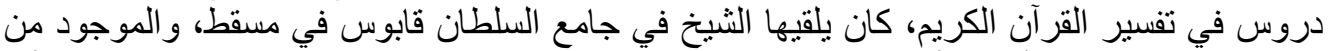

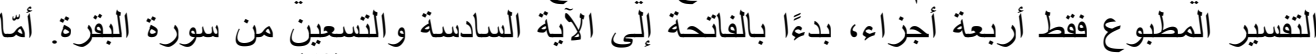
الجزء الر ابع فخاض في الآية السابعة من آل عمران حول المعاء المحكم و المتشابه. (50)

\section{المطلب الأوّل: الإسقاطات التاريخيّة وأثر ها على تأسيس عقائد الإباضيّة}

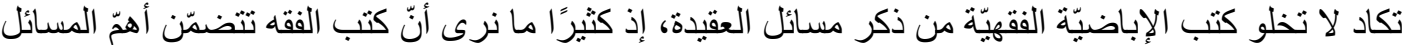

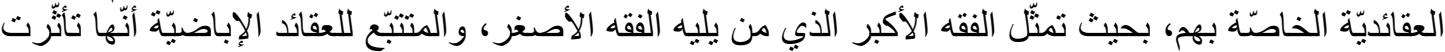

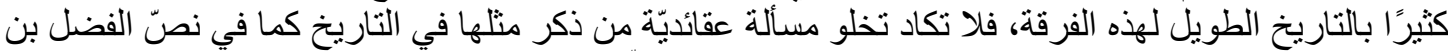

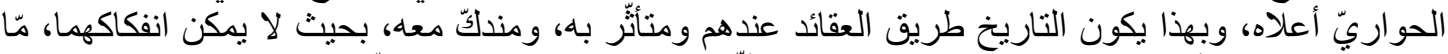

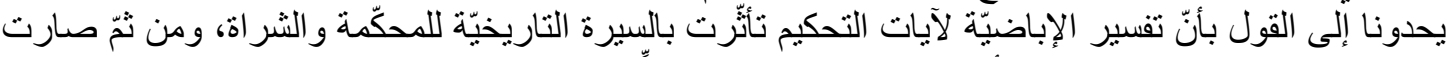

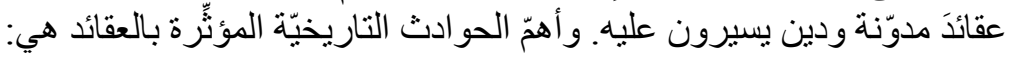

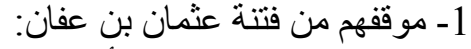

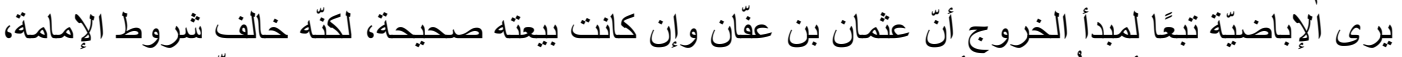

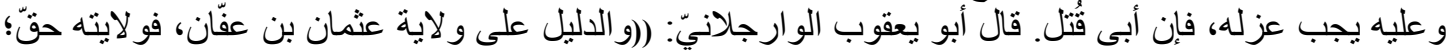
لانطباق أهل الثورى عليه، و عزله وخله وله وله وقتله حقّ؛ لانتهاكه الحرم الأربع: 


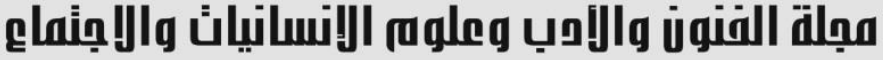

Journal of Arts, Literature, Humanities and Social Sciences www.jalhss.com

أو لاها: استعماله الخونة والفجرة على الأمانة التي عرضها الله تعالى على السماوات والأرض والجبال فأبين أن

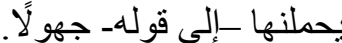
و الثانية: ضربه الأبشار و هتكه الأستار من الصحابة الأخيار إن أمروه بالمعروف ونهوه عن المنكر ، كأبي ذر

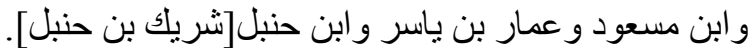

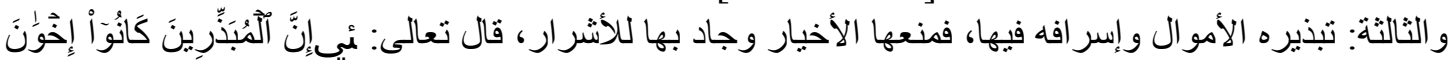

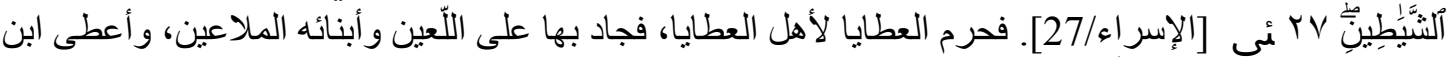

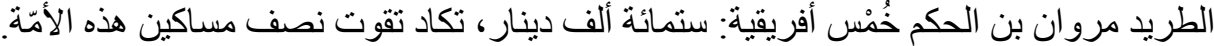

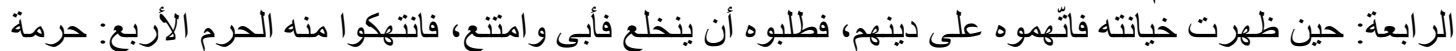

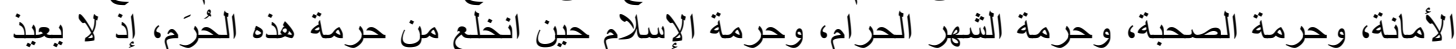

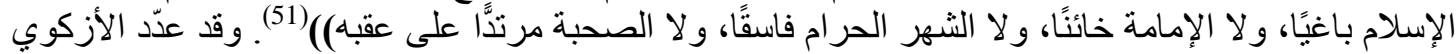

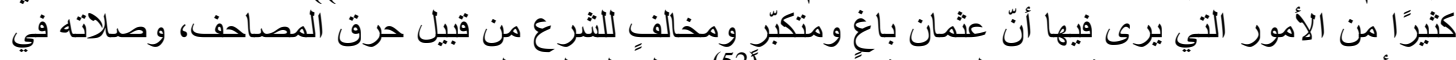

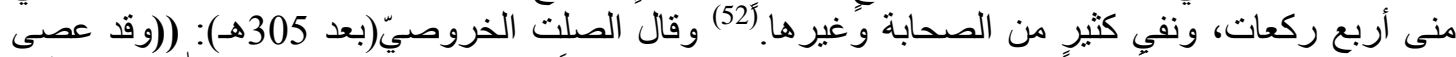

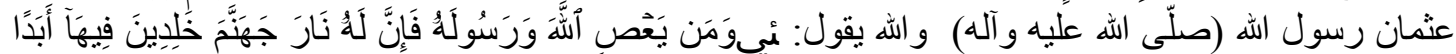

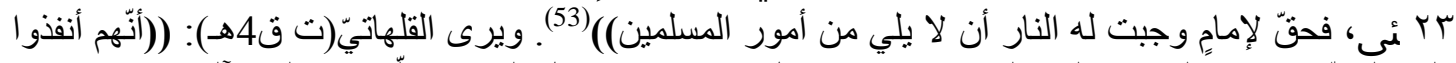

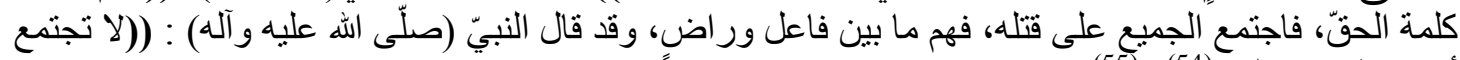

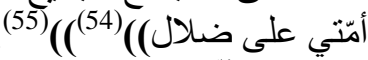

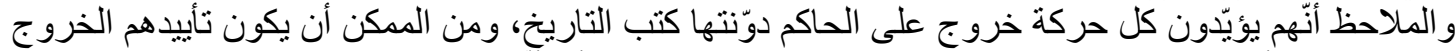

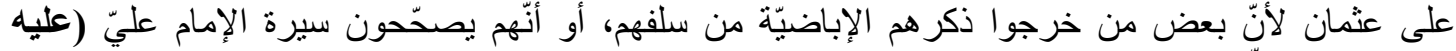

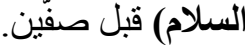

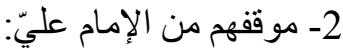

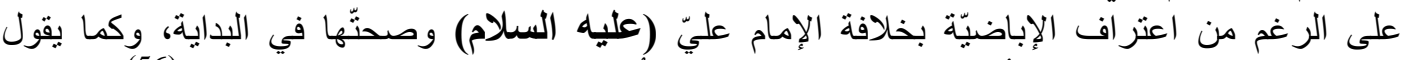

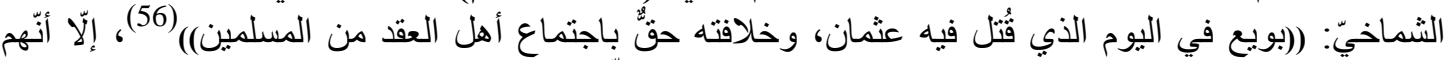

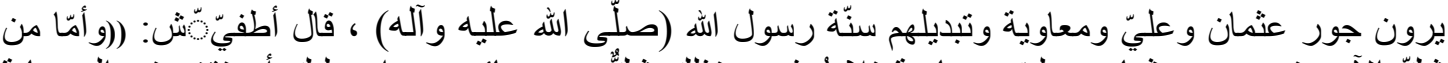

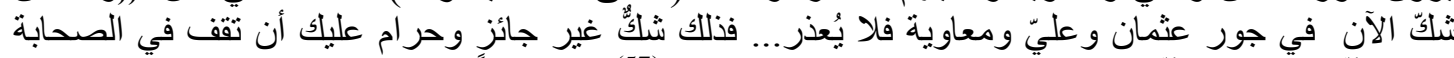

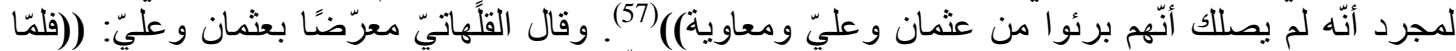

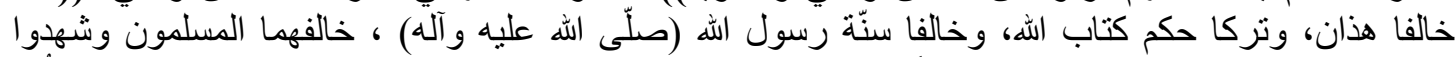

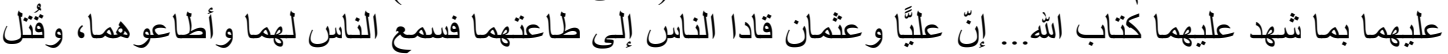

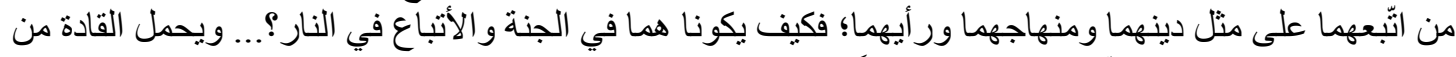

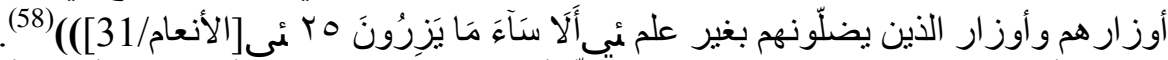

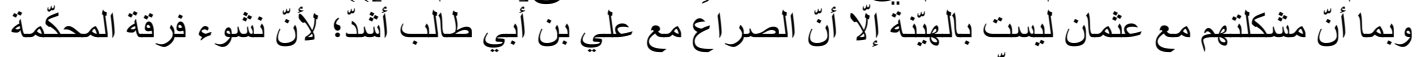

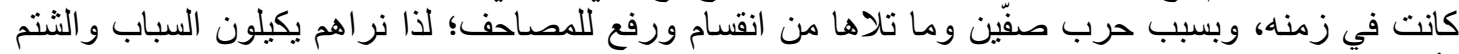

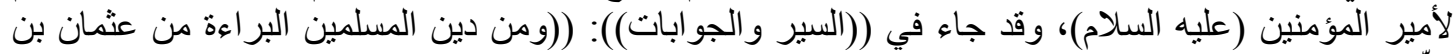

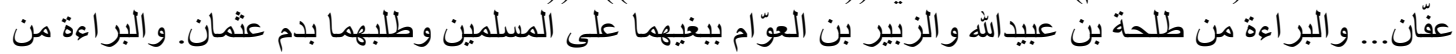

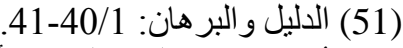
(52) يُنظر : كثثف الغمّة الجامع لأخبار الأمَّة: 158/2 وبعدها.

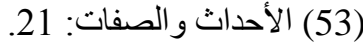
(54) سنن الترمذيّ: 36/4، حديث رقم(21/2) الكيّة 2167)، وقال: هذا حديث غريب. 221/2 (55) الكثف و البياني: 


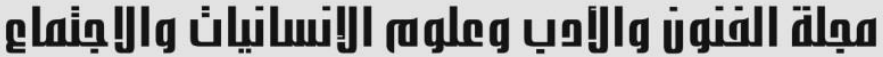

Journal of Arts, Literature, Humanities and Social Sciences www.jalhss.com

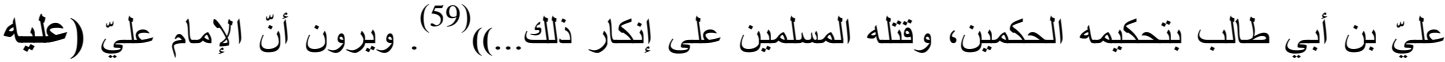

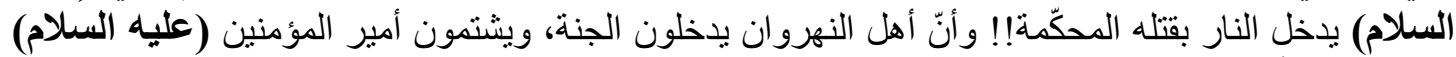

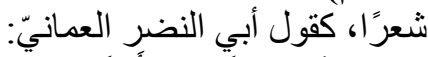

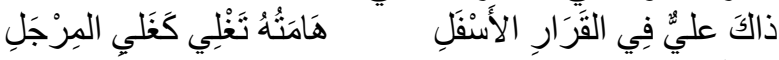
وقو له:

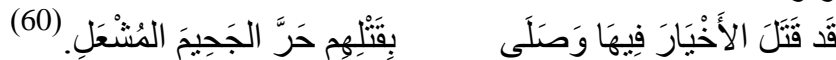

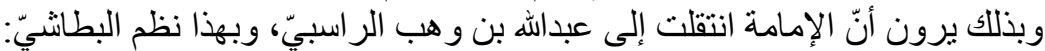

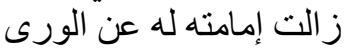
من لم يكن في دينه أمينا (61) يختار من بختار هـ للأمّة للار اسبيّ بدفعن عنهُ.

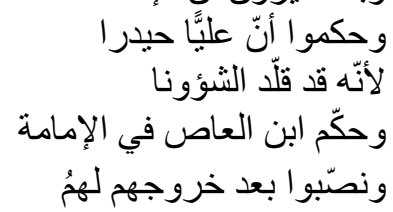

يقول الأزكويّ في باب (الأئمة الذين باعوا أنفسهم لله في إنكار المنكر ): (فأوّّلهم عبداله بن وهب الر اسبيّ، إمام

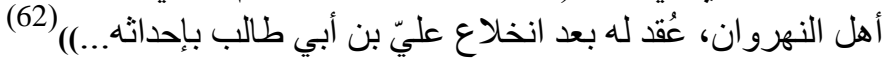

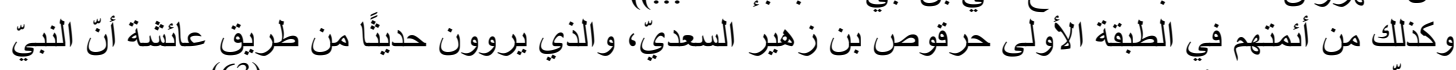

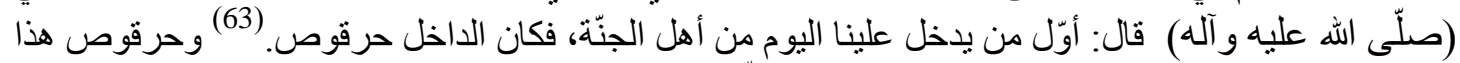

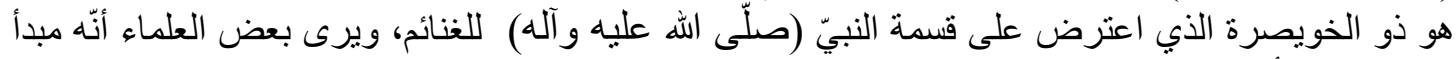
الخوارج كما أسلفنا.

و العجيب أنّ تطاولهم لم ينتوقّف على الإمام عليّ (عليه السلام) بل تعدّى للإِمام الحسن (عليه السلام)، فقال

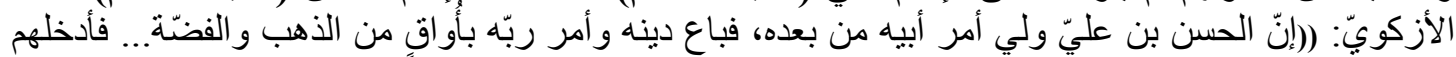

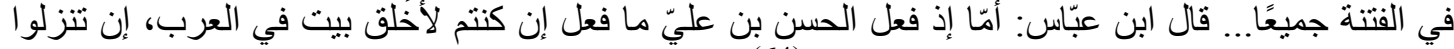

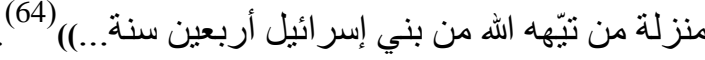

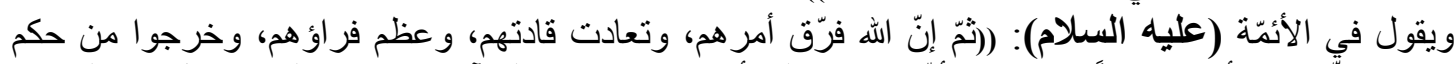

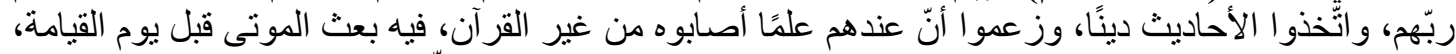

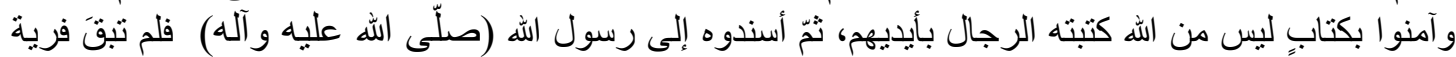
أعظم على الله من فريةٍة على رسول الله منهم)(65).

المطلب الثاني: آيات التحكيم عند مفسري الإباضيّة:

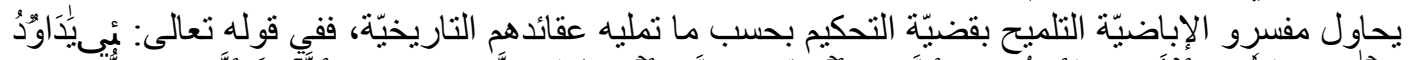

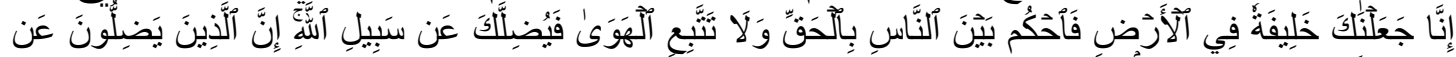

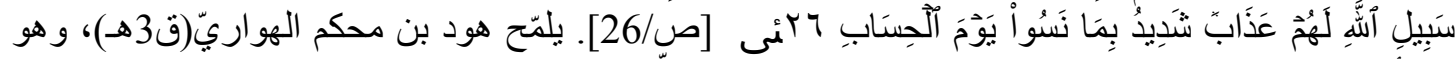

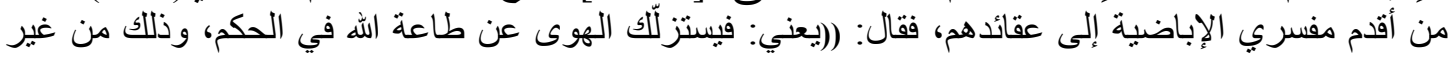

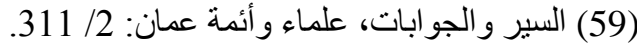

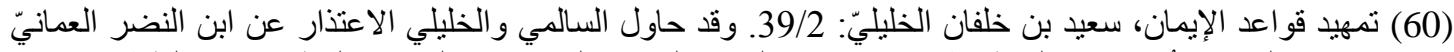

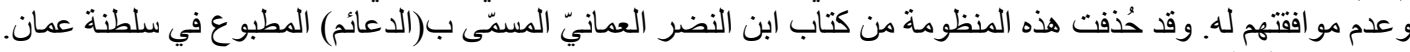




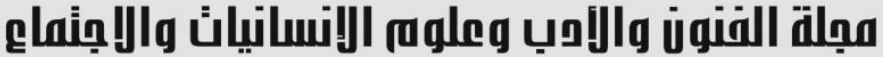

Journal of Arts, Literature, Humanities and Social Sciences www.jalhss.com

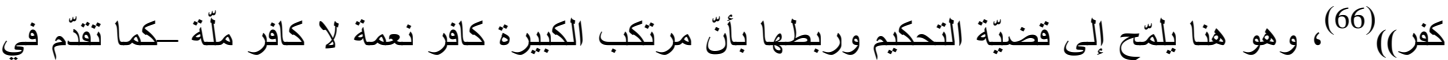

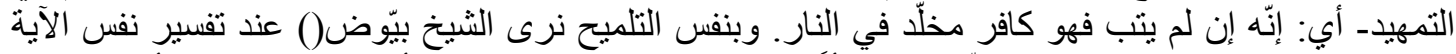

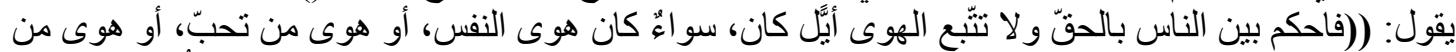

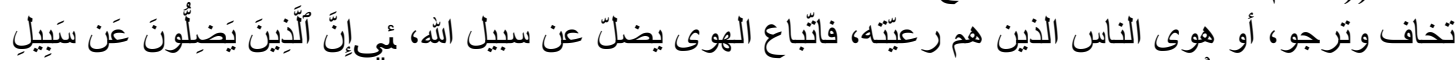

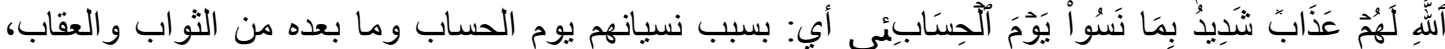

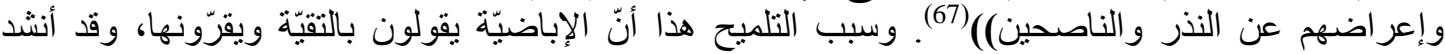
السالمي:

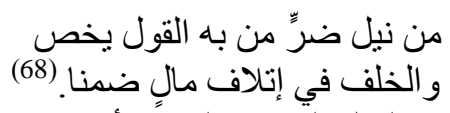

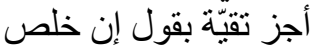

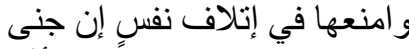

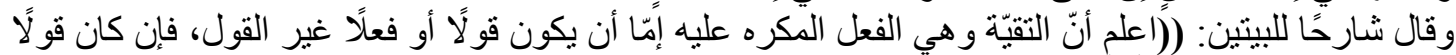

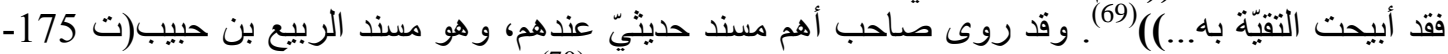

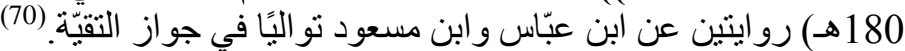

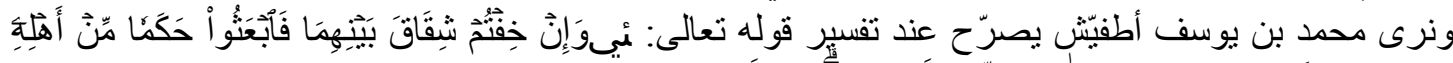

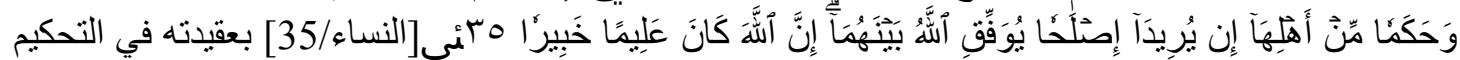

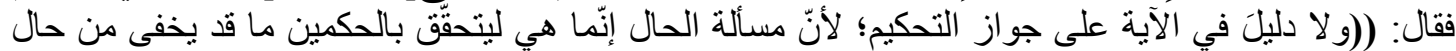

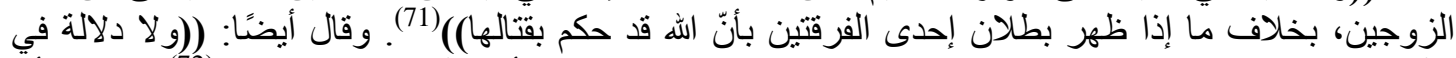

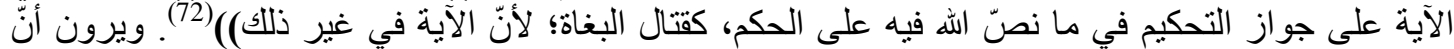

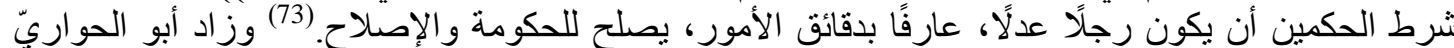

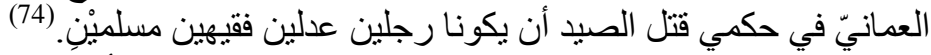

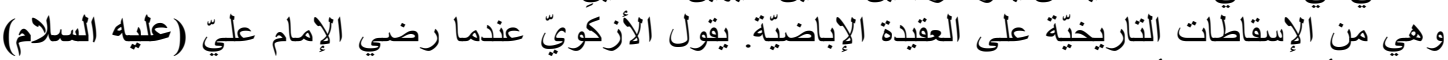

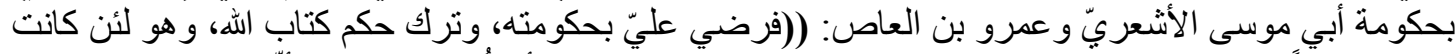

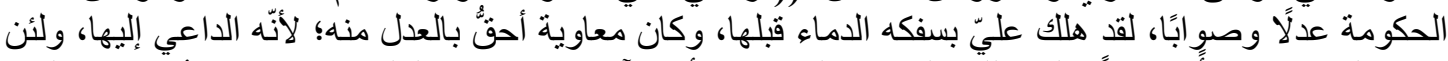

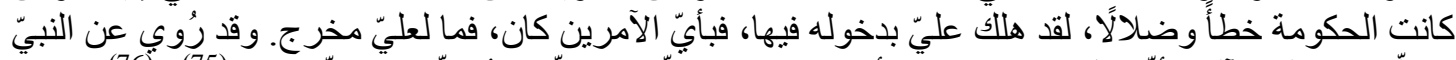

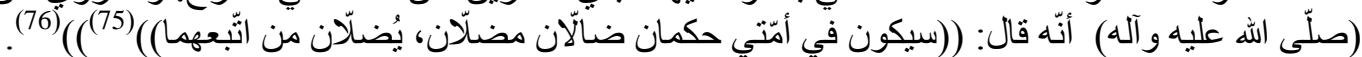

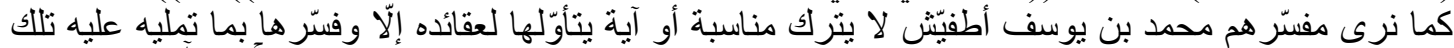

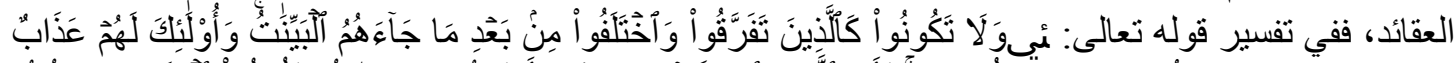

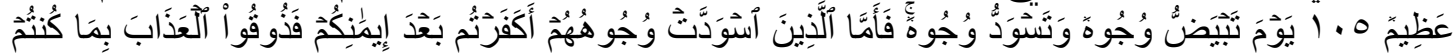

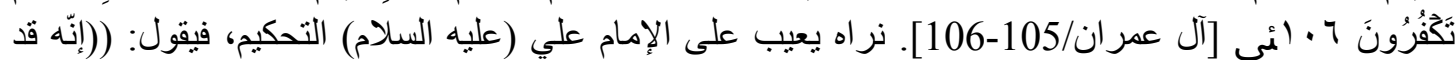

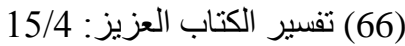

(67) في رحاب القرآن (مختصر تفسير العلامة الثيخ بيوض): من سورة بس إلى نهاية سورة الاخان: 133.

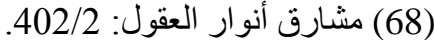

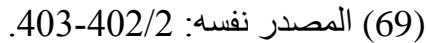

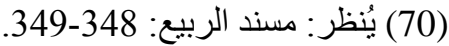

(71) (72) هميان الزاد إلى المعاد: 533/4.

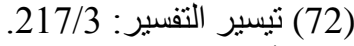

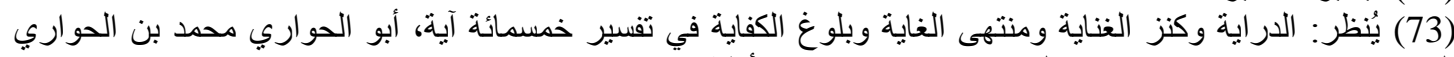

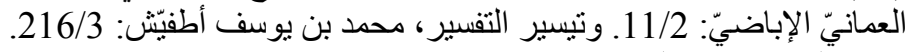

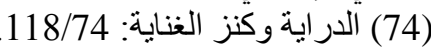

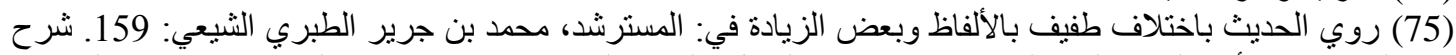

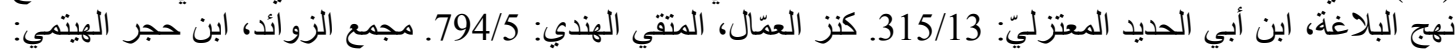




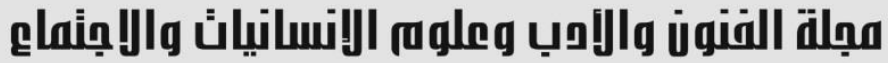

Journal of Arts, Literature, Humanities and Social Sciences www.jalhss.com

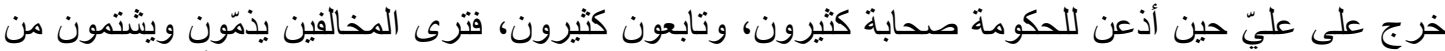

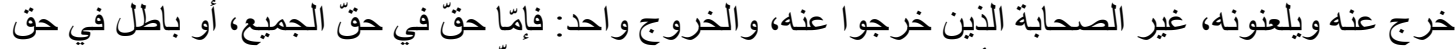

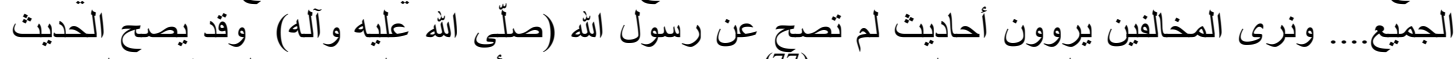

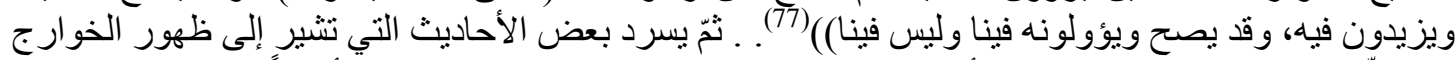

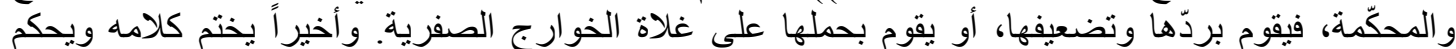
بالقول: (وو الدليل الأقوى على أنّ تلك الأحاديث ليست فينا، و لا فيمن التتدينا بهم، وأنّ الراضيرة اضين بالتحكيم هم

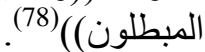

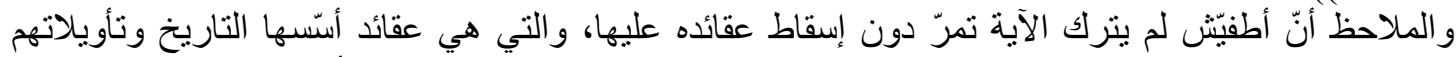

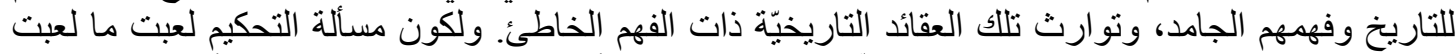

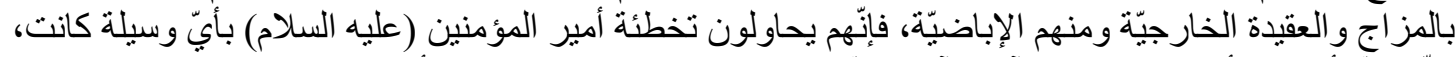

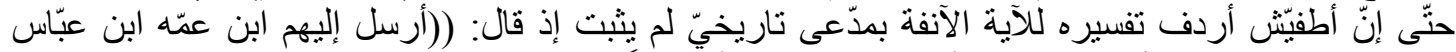

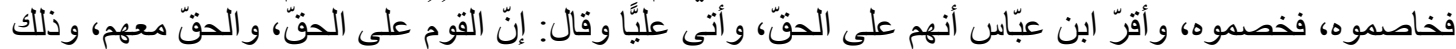

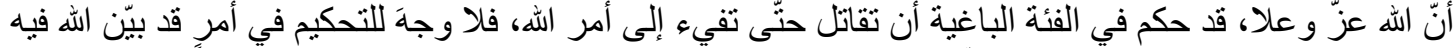

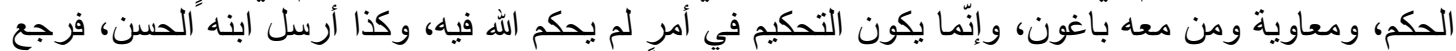

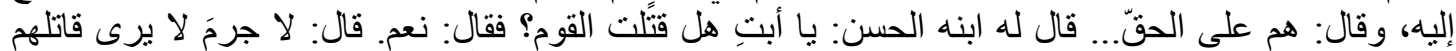

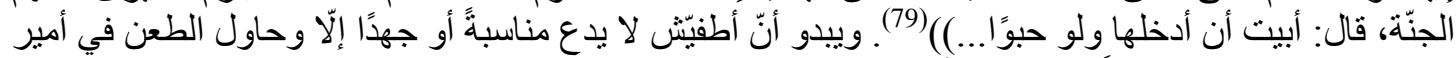

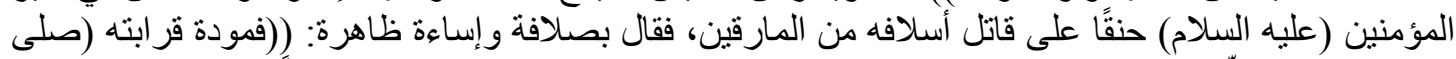

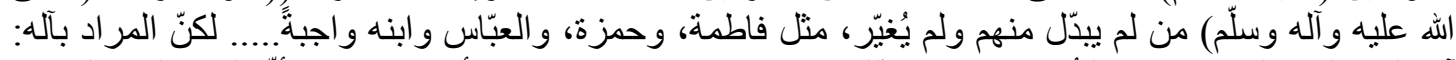

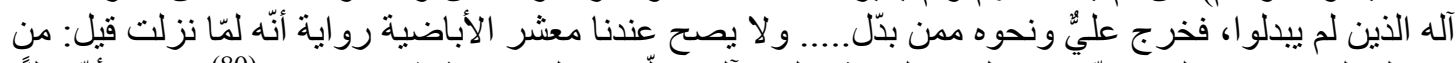

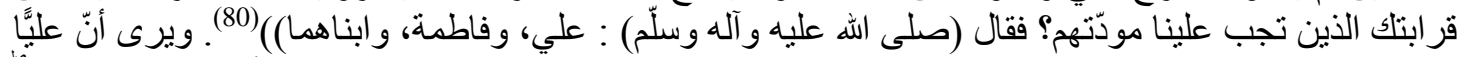

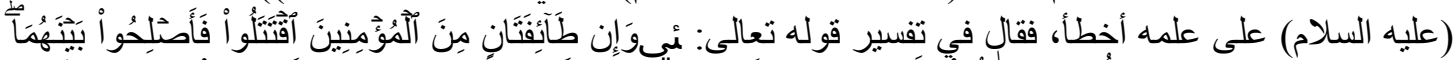

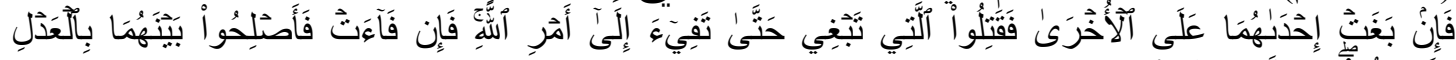

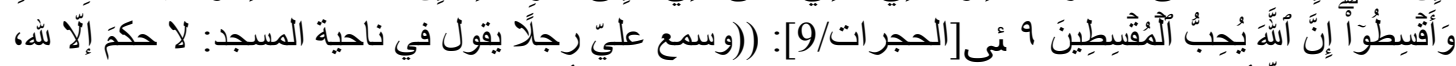

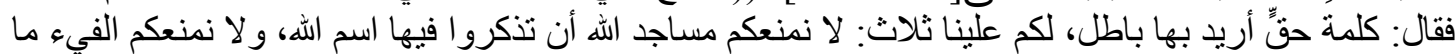

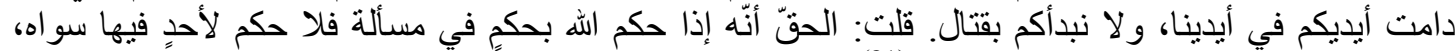

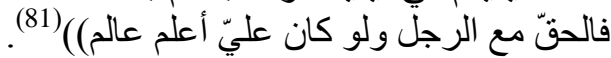
وقد أفرد ناصر السابعيّ للمطارحات في آيات التحكيم مكانًا في كتابه ((الخوارج والئ والحقيقة الغائبة)) تعرّض

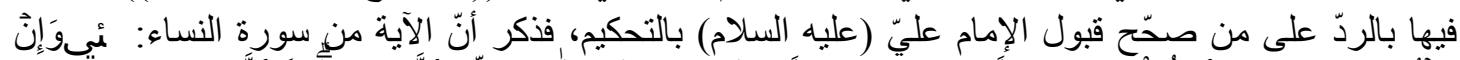

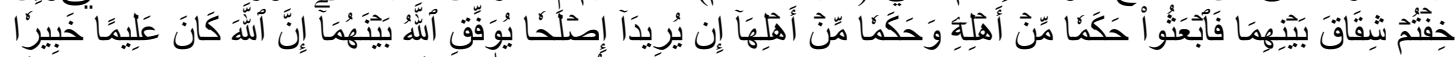

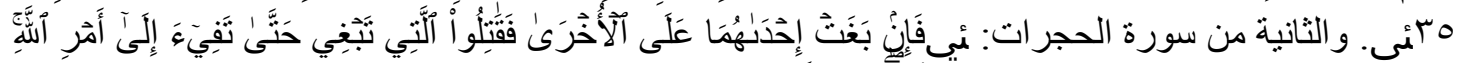

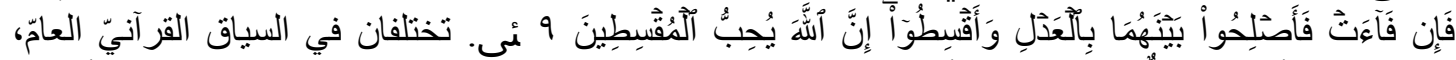

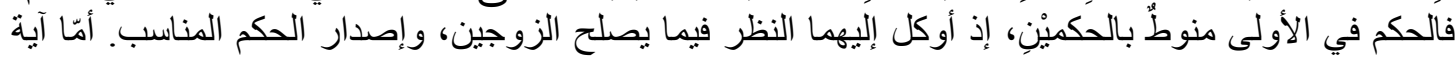

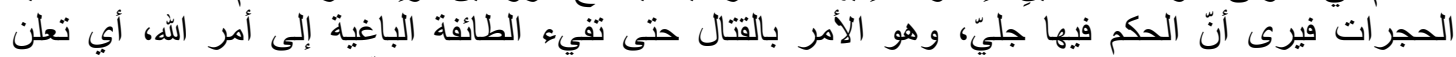

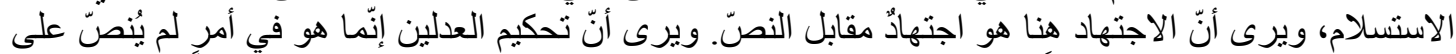

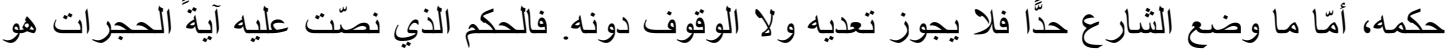




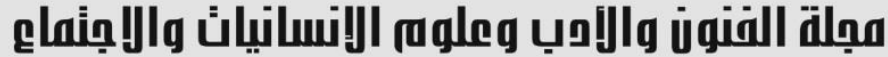

Journal of Arts, Literature, Humanities and Social Sciences www.jalhss.com

قتال الفئة الباغية حتى تفيء إلى أمر الله، ويؤكّد أنّ أهل حروراء يرون أنّ قتال عليّ لأهل الثام كان امتثالًا

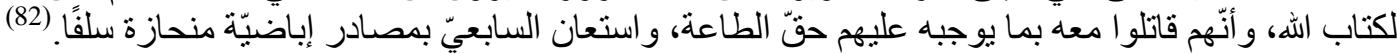

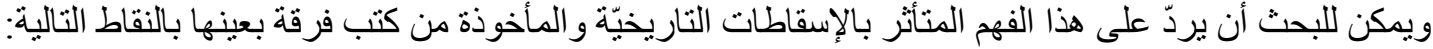

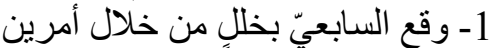

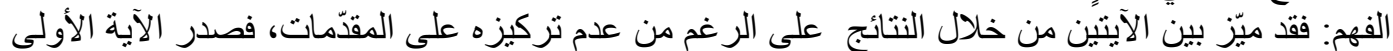

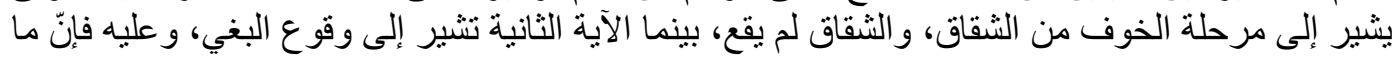

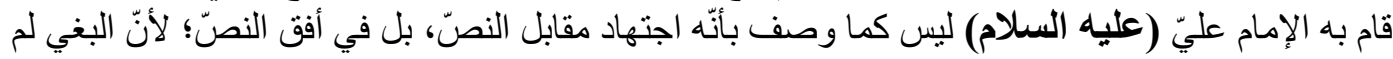

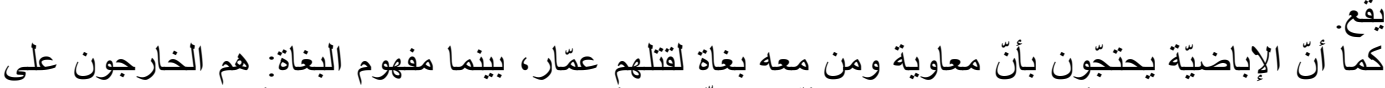

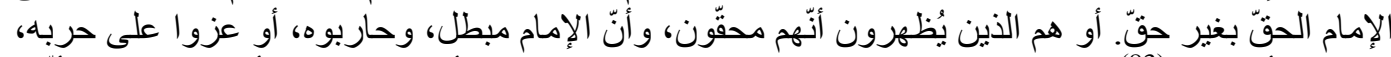

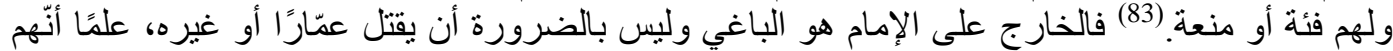

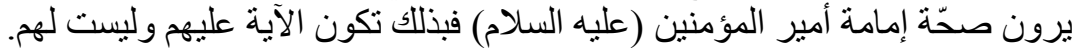

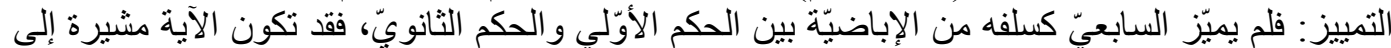

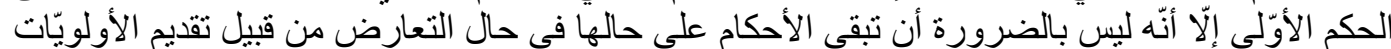

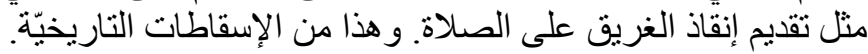

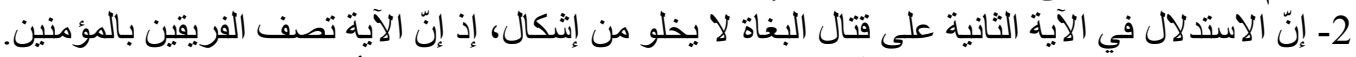

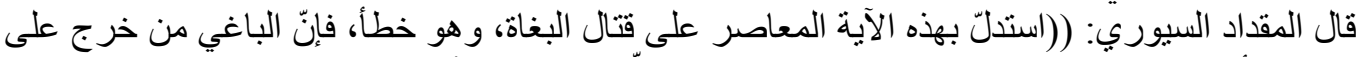

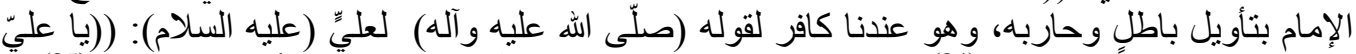

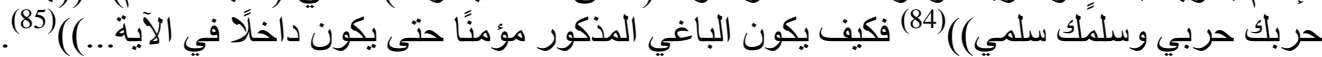

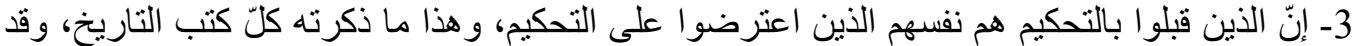

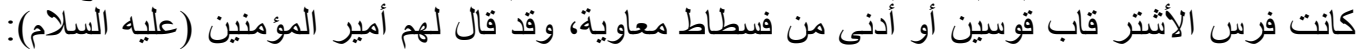

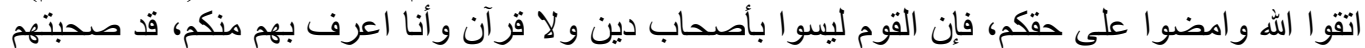

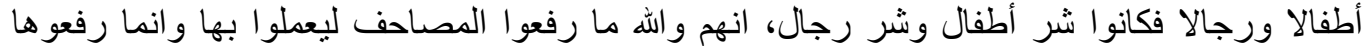

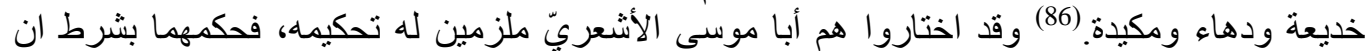

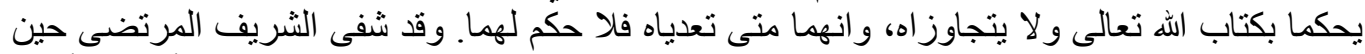

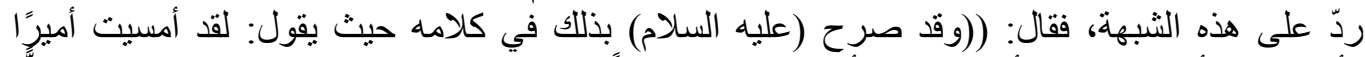

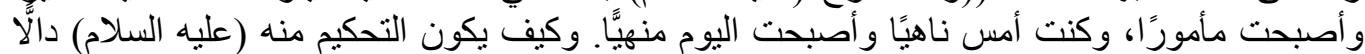

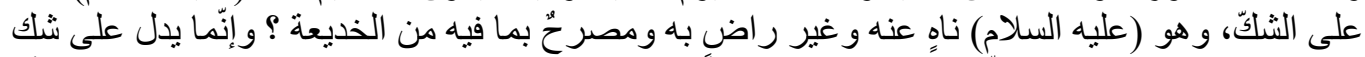

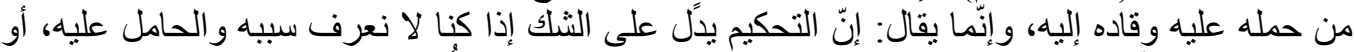

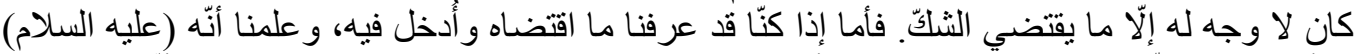

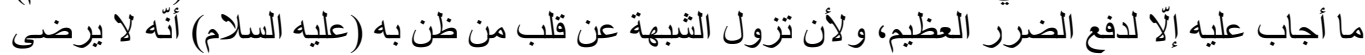

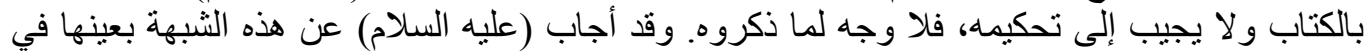
مناظرتهم لما قالو اله: أنشككت ؟ فقال عليه السلام: أنا أولى بأن لا أثنك في ديني أم النبي صلى الله عليه

(82) يُنظر : الخوارج و الحقيقة الغائبة، ناصر بن سليمان بن سعيد السابعيّ: 95. و ويُنظر : الموجز ، أبو عمّار عبدالكافي بن

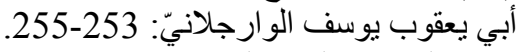

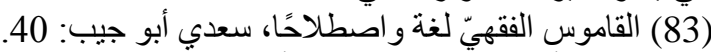

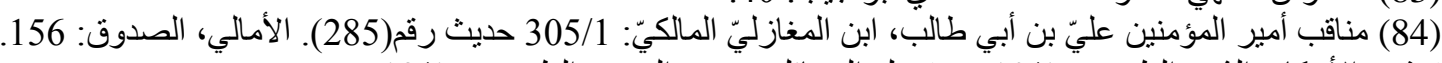

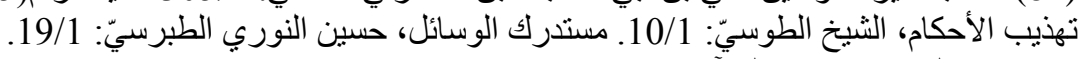




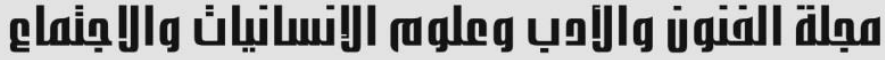

Journal of Arts, Literature, Humanities and Social Sciences www.jalhss.com

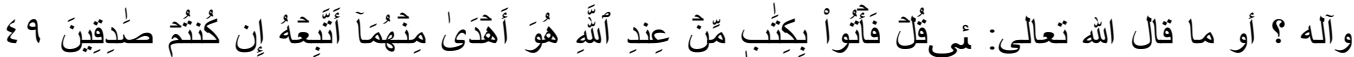

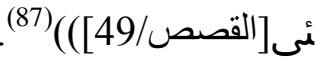

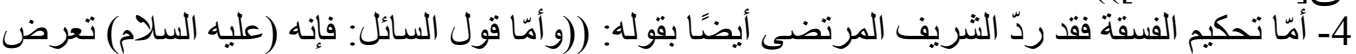

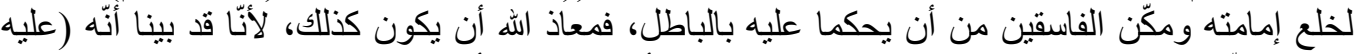

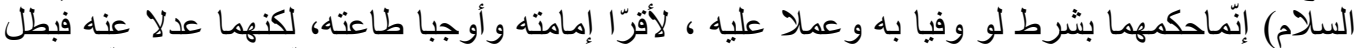

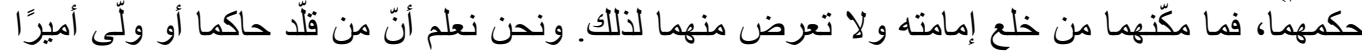

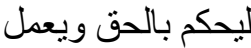

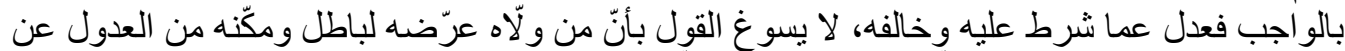

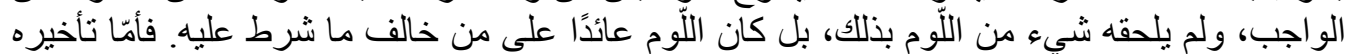

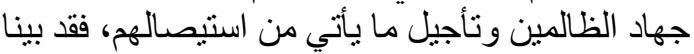

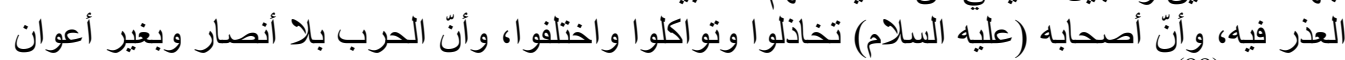

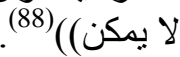
كما لا يخفى أنّ المفسّرين وقعو ا تحت وطأة الرواية التاريخيّة لجماعتهم وفرقتهم، فنر اهم يروون أحسات أحداث

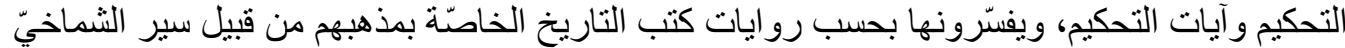

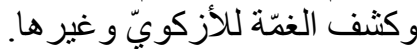

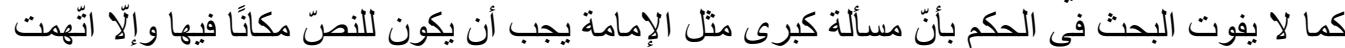

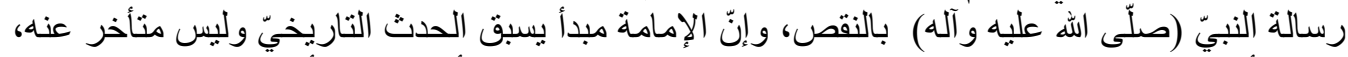

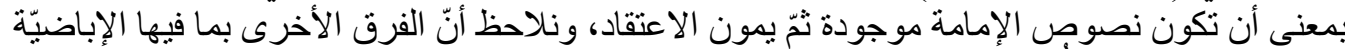

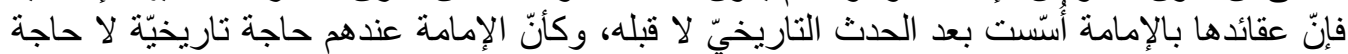

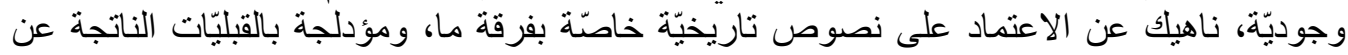

الإسقاطات التاريخيّة.

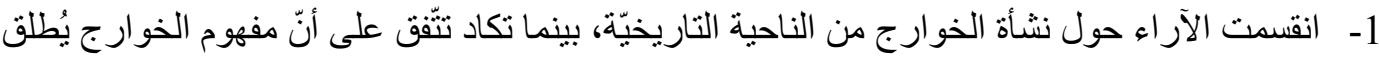

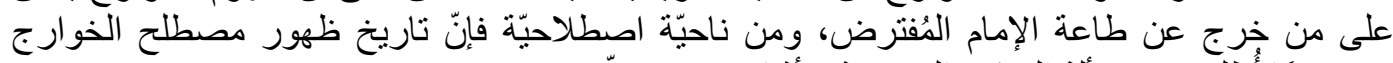

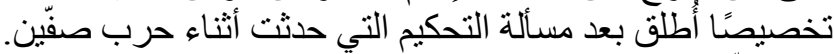

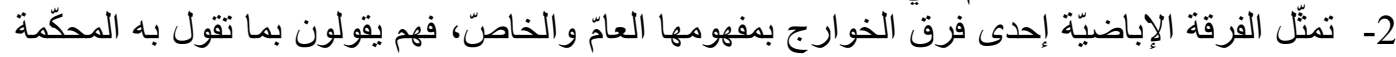

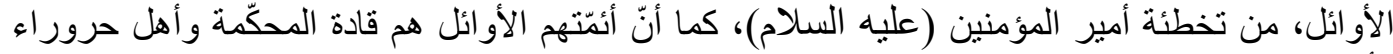

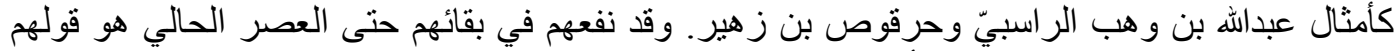

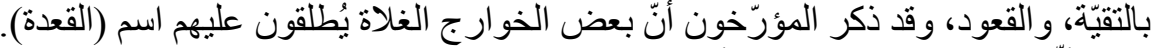

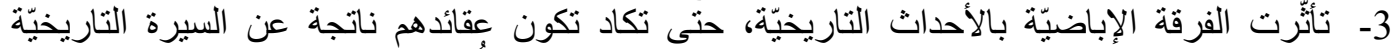

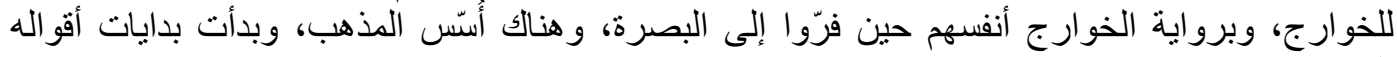

الكلاميّة.

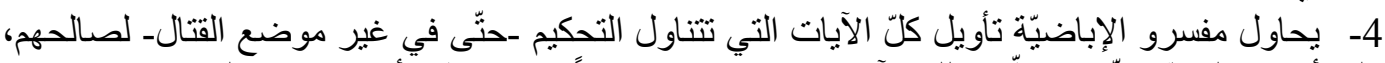

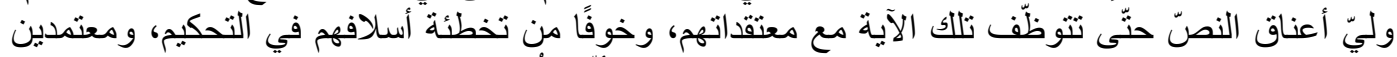

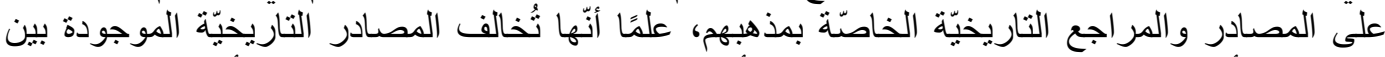

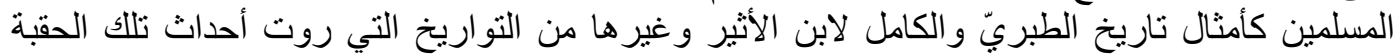

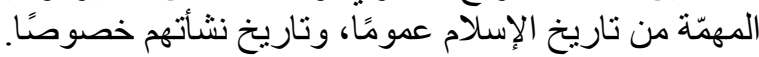




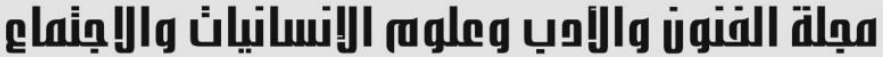

Journal of Arts, Literature, Humanities and Social Sciences www.jalhss.com

5- أخذ مذهب الإباضيّة الكثير من أقوال المعتزلة، وخاصّة القول بالمجاز، وربّما كان الغرض منها تأويل الآيات و الأحداث لصالح فريقهم، فالأخذ أخذ نفعيّ لا إقتنتاعيّ.

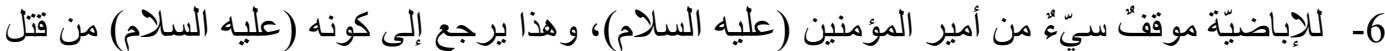

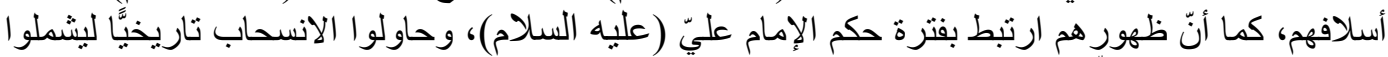

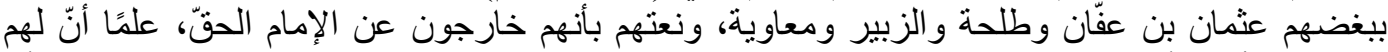

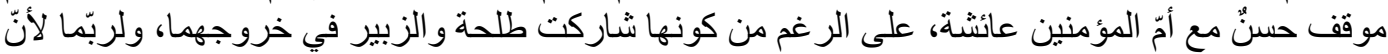

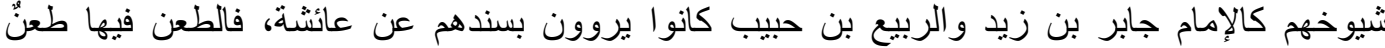
بأحاديثهم، و هذه من الأمور النفعيّة أيضًا لا لا الاقتناعيّة.

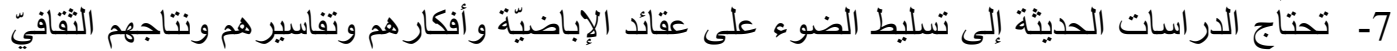

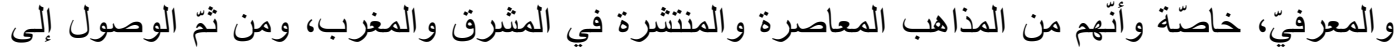

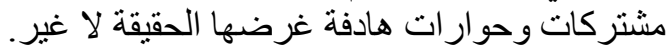

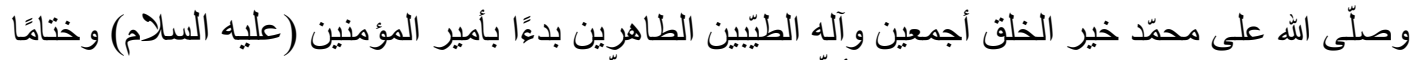

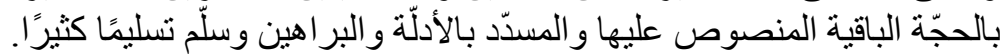

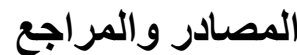

1- الأباضية بين الفرق الإسلامية، علي يحيى معمر، ط2، وزارة التراث القوميّ والثقافة، 1415هـ-1994م، سلطنة عمان. 2- الأباضية في مصر و المغرب، د. رجب محمد عبدالحليم، وزارة التراث القوميّ والثقافة، سلطنة عمان، 1410 هـ 140

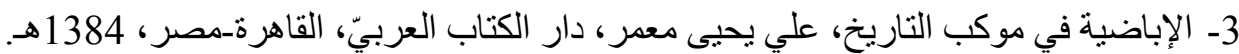

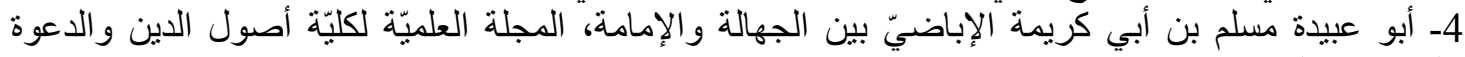

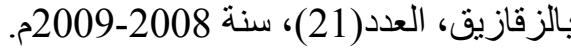
5- الأحداث و الصفات، أبو المؤثر الصلت بن خميس الخروصيّة(بعد 305هـ)، تحقيق: د. جاسم ياسين محمد

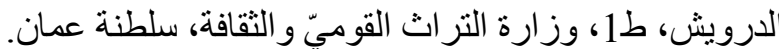

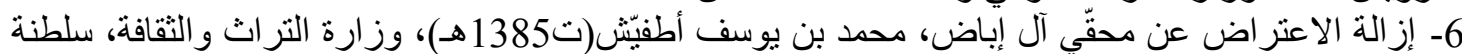

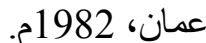

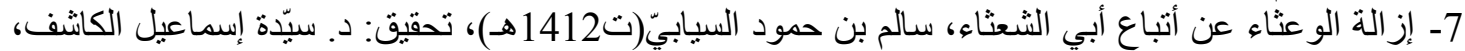

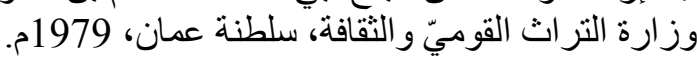

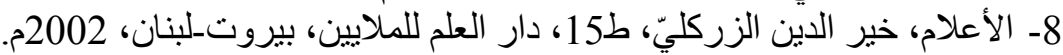

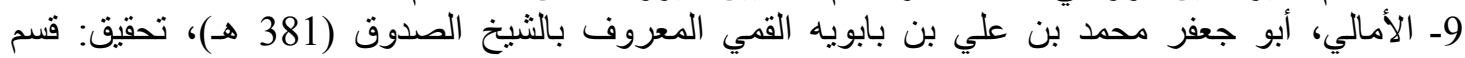

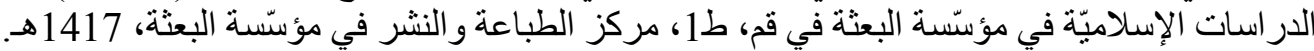

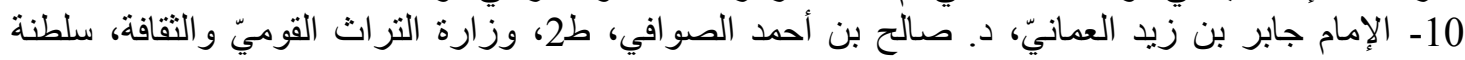

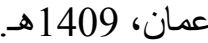
11- بحوث في الملل والنحل، جعفر السبحانيّ، ط1، مؤسّسة الإمام الصادق (عليه السلام)، قم المقدّسة_إيران، هـ 1427 12- بدء الإسلام وشرائع الدين، لوّاب بن سلاًّم المزاتي الإباضيالأباضي(ت 273هـ)، تحقيق: فيرنر شفارنس

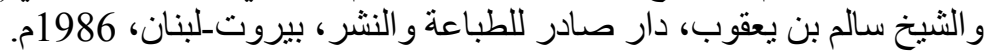

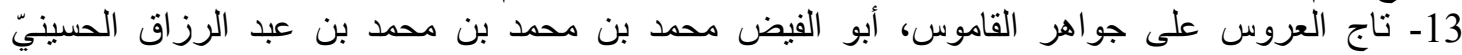

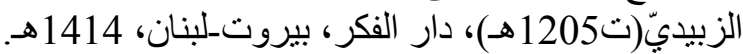

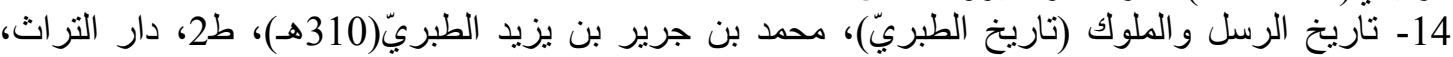

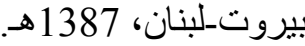

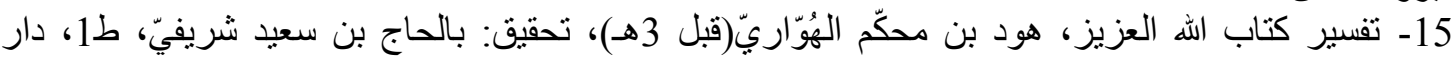

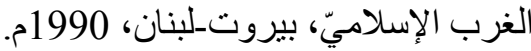




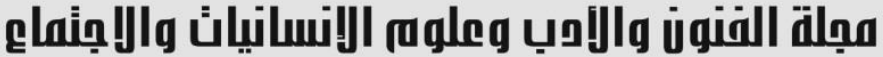
www.jalhss.com

16- تلبيس إبلبس، جمال الدين أبو الفرج عبدالرحمن بن عليّ بن محمد ابن الجوزيّ(ت597هـ)، ط1، دار القلم،

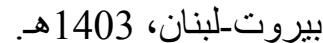
17- تمهيد قواعد الإيمان، سعيد بن خلفان الخليليّ، ط1، مكتبة الثيخ محمد بن شامس البطّاتشيّ للنشر والتوزيع،

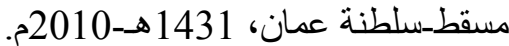
18- تنزيه الأنبياء، علم الهانى ابو القاسم السيد على الهي بن حسين بن موسى المعروف بالثريف المرتضى هو

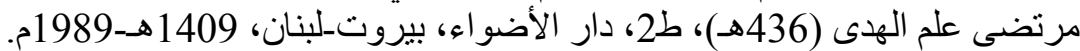

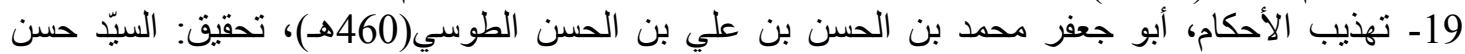

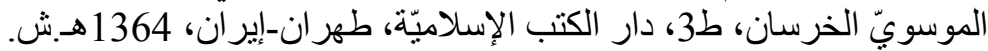

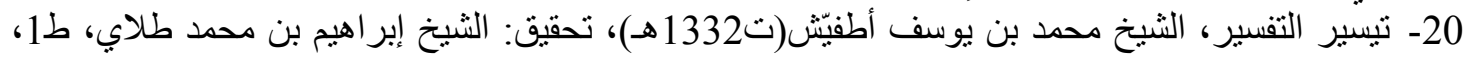

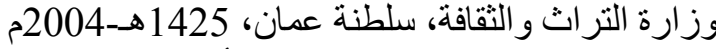

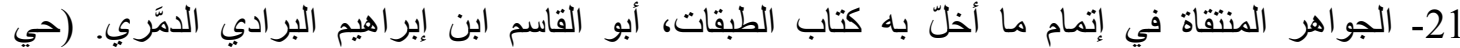

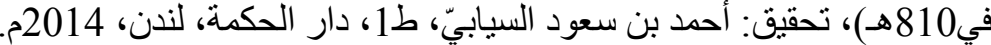

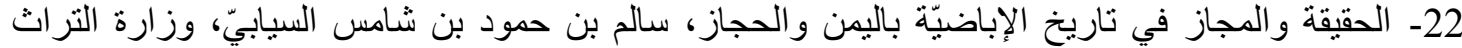

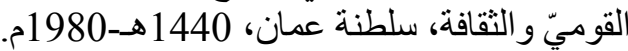

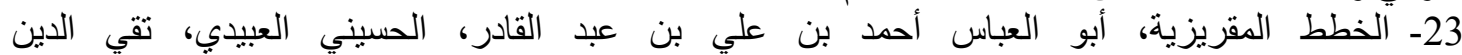

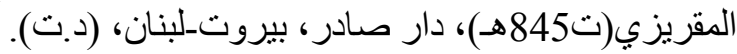
24- الخوارج والحقيقة الغائبة، ناصر، بندرون سليمان بن سعيد السابعيّ، دار المنتظر، بيروت_لبنان، 1420هــ 2000 25- داعية الكلمة الطيّبة السيرة العلميّة للشيخ العلّامة أحمد بن حمد بن سليمان الخليليّ المفتي العام لسلطنة

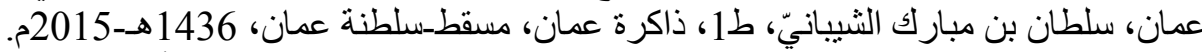

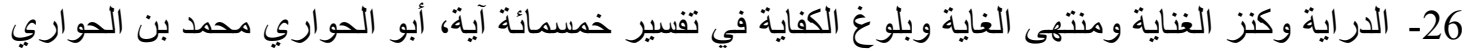

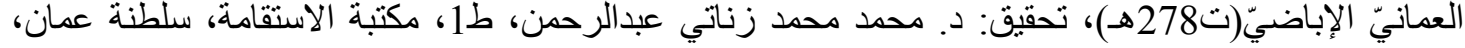

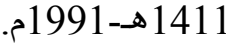

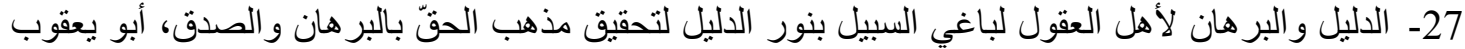

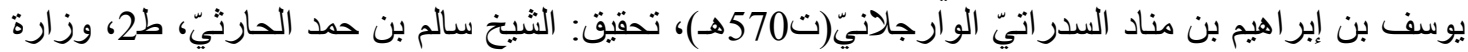

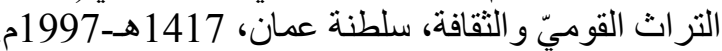

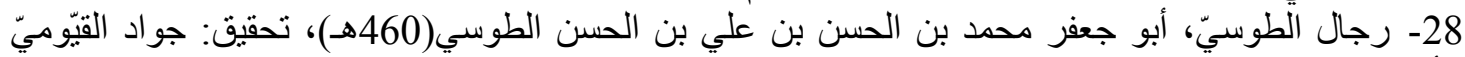
الأصفهانيّ، ط5، مؤسّسة النشر الإسلامي التاربعة لجماعة المدرسين في قم المقدسة، قم المقدسة، إيران، هـ 1430 29- رسالة شافية في بعض التواريخ، الثيخ محمد بن يوسف أطفيّش(ت1332هـ)، طبعة حجريّة، الجزائر، 1299 30- سلاسل الذهب في الأصول والفروع و الأدب، محمد بن شامس البطّاثشيّ، وزارة التراث القوميّ والثقافة،

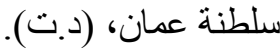

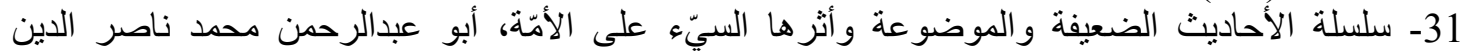

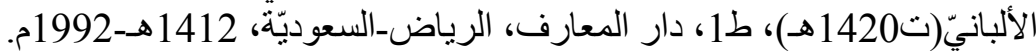

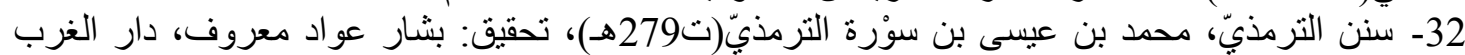
الإسلاميّ، بيروت_لبنان، الترمي، 1998م. 33- سنن النسائي، أبو عبدان، الرحمن أحمد بن شعيب بن عليّ الإنيّ النسائيّ(ت303هـ)، تحقيق: عبدالفتاح أبو غدة، ط2،

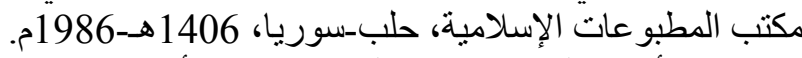
34- سير أعلام النبلاء، شمس الإين محمد بن أحمد بن عثمان الذهبيّ(ت748هـ)، تحقيق: بشار عو اد معروف،

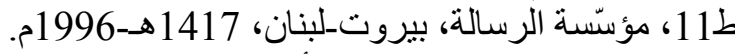

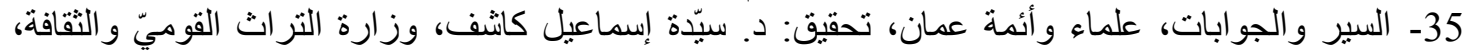
سلطنة عمان، 1406 هـ-1986م. 


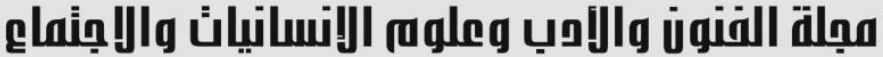

Journal of Arts, Literature, Humanities and Social Sciences www.jalhss.com

36- السير، أحمد بن سعيد بن عبدالواحد الثماخيّ(توبـهـهـ)، تحقيق: أحمد بن سعود السيابيّ، ط2، وزارة

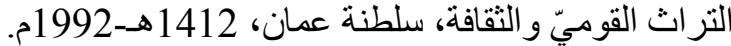

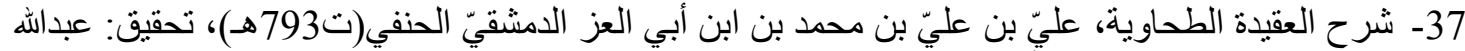

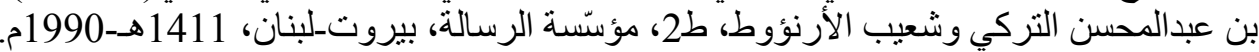

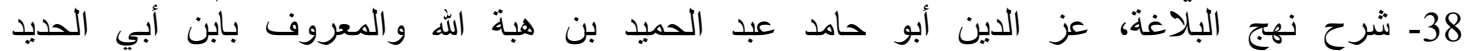

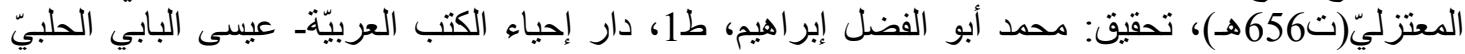
وشركاه، بيروت_لبنان، 1378 هـ-1959)، 1959م.

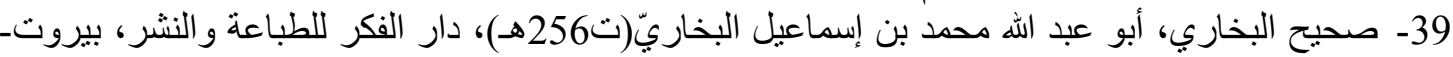

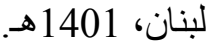

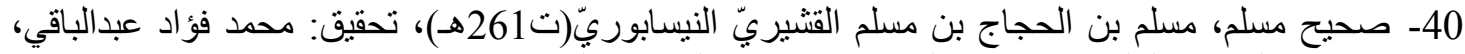

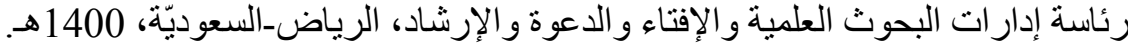

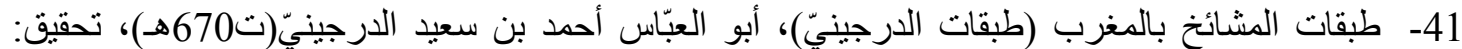

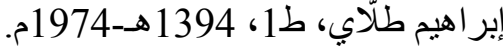
42- العقود الفضيّة في أصول الإباضيّة، سالم بن حمد بن سليمان الحارثيّ، وزارة التراث القوميّ و الثقافة،

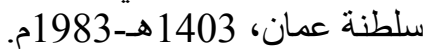

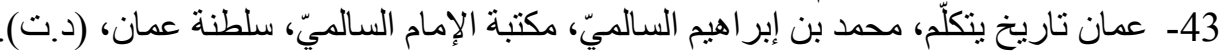

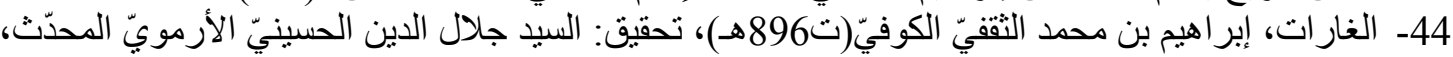

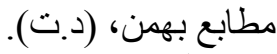
45- الفرق الإسلاميّة في الثمال الإفريقيّ، ألفرد بل، ترجمة: عبدالرحمن بدويّ، ط3، دار الغرب الإسلاميّ،

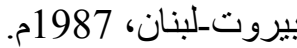
46- الفرق بين الفرق، أبو منصور عبدالقاهر بن طاهر بن محمد البغداديّ التميميّ الأسفرايينيّ(ت439هـ)،

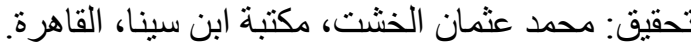
47- الفصل في الملل والأهواء و النحل، أبو محمد علي بن أحمدة بن بن سعيد بن حزم الظاهريّ(ت456هـ)، دار المعرفة، بيروت_لبنان، 48- الفكر السياسيّ عند الإباضيّة و الزيديّة، د. سالم بن هلال الخروصيّ، ط1، مكتبة مدبولي، القاهرة-مصر، 2006

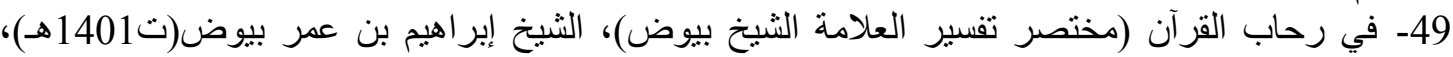

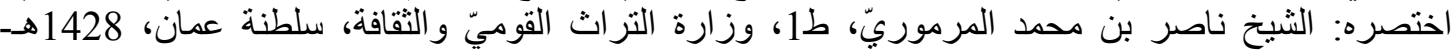

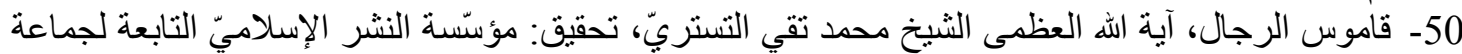

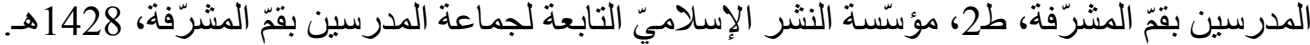

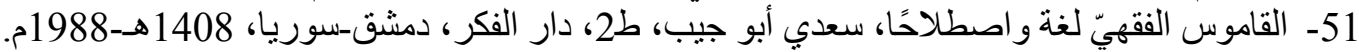

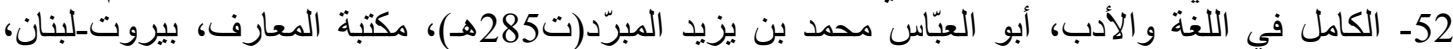

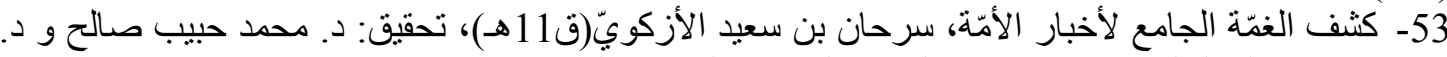

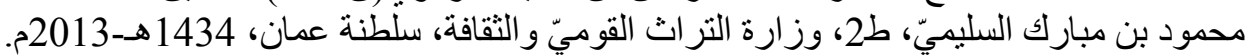

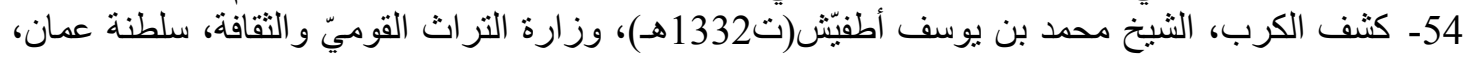

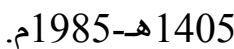
55- الكثف و البيان، أبو عبداله محمد بن سعيد الأزديّ القلهاتيّ(ت ق4هـ)، تحقيق: د. سيّّة إسماعيل كاشف،

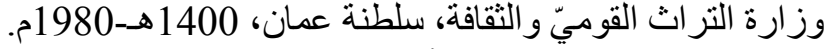

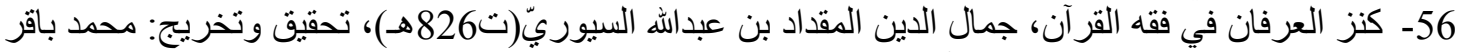

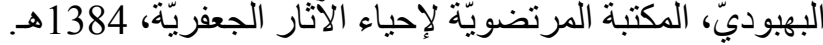




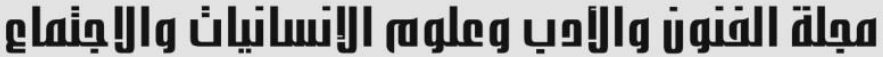

Journal of Arts, Literature, Humanities and Social Sciences www.jalhss.com

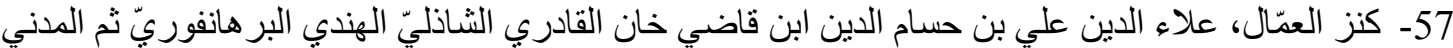

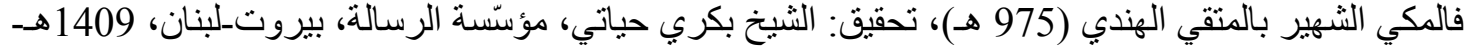

58ـ اللمعة المرضيّة من أنَّة الإباضية، نور الدين السالميّ، ط1، ذاكرة عمان، سلطنة عمان، 1435هـ2014

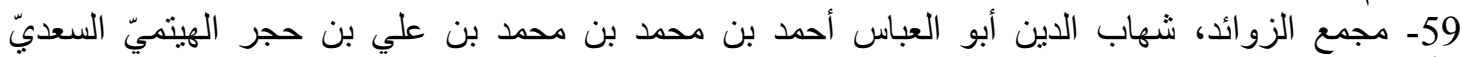

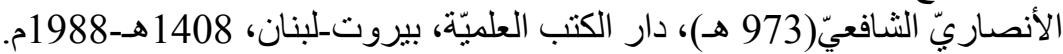

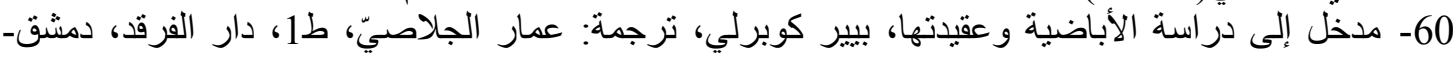

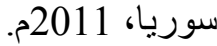

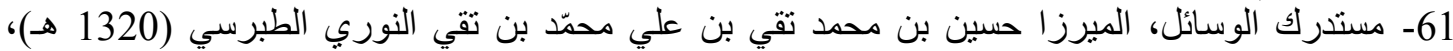

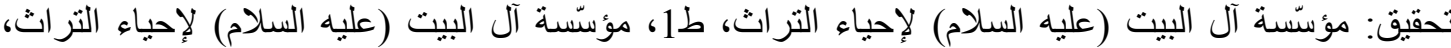

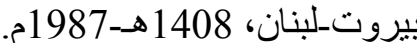
62- المسترشد، أبو جعفر محمد بن جرير بن رستم الطبري الآملي(بعد 410هـ)، تحقيق: الثيخ أحمد المحموديّ،

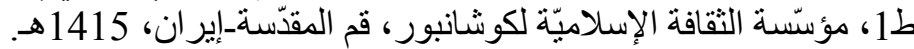

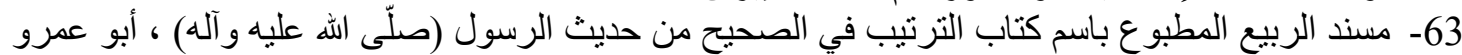

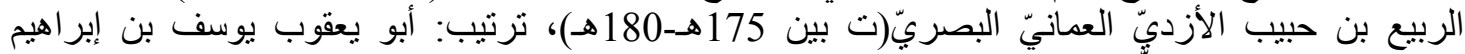

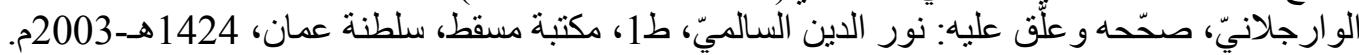

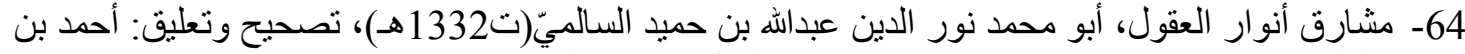

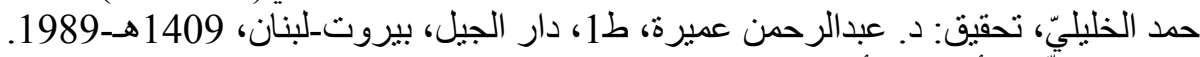

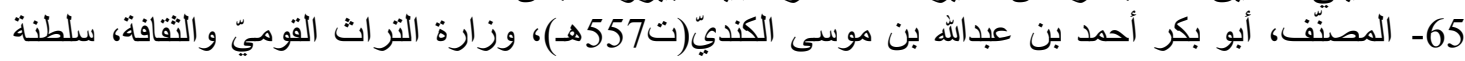

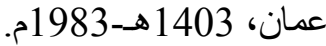
66- معالم الدين، عبدالعزيز بن إبر اهيم الثمينيّ المصعبيّ(ت1220هـ)، وزارة التراث القوميّ و الثقافة، سلطنة

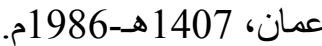
67- معجم أعلام الإباضية، د. محمد صالح ناصر، ، وسلطان بن مبارك الثيبانيّ، ط1، دار الغرب الإسلاميّ،

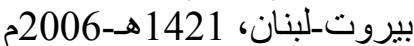

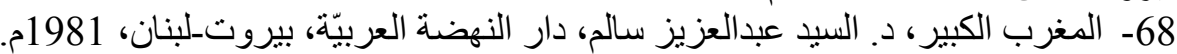

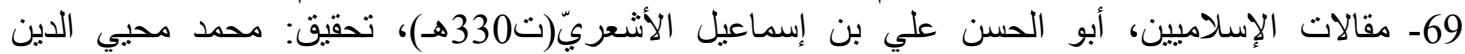

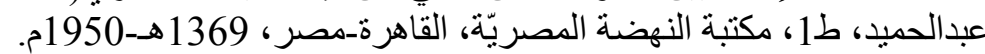

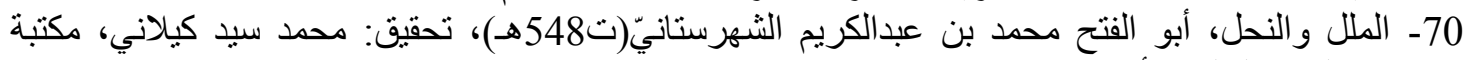

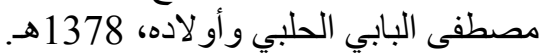

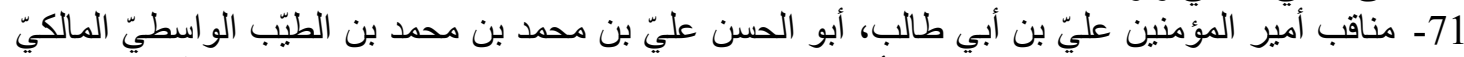

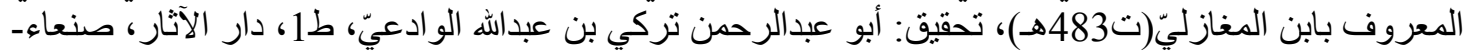

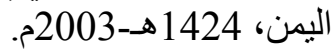

72- الموجز، أبو عمّار عبدالكافي بن أبي بعقوب يوسف الوارجلانيّ(ت570هـ)، وزارة الثقافة، سلطنة عمان، 2013

73- نشأة الحركة الإباضيّة، مروان خليفات، ط1، وزارة التراث و الثقافة، مسقطـعمان، 1423 هـ-2002م.

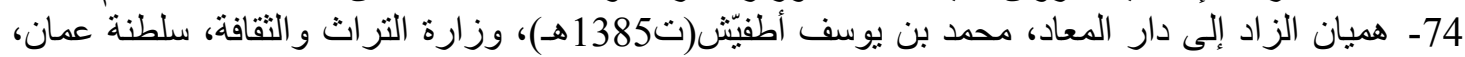




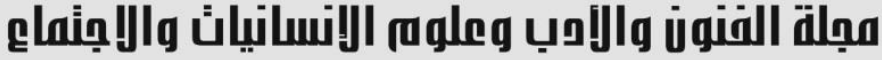 \\ Journal of Arts, Literature, Humanities and Social Sciences www.jalhss.com}

Volume (53) June 2020

العدد (53) يونيو 2020

\section{References}

1. Al-Ibadiya between the Islamic groups, Ali Yahya Muammar, 2nd Edition, Ministry of National Heritage and Culture, 1415AH-1994AD, Sultanate of Oman.

2. Ibadi in Egypt and Morocco, d. Rajab Muhammad Abdul-Halim, Ministry of National Heritage and Culture, Sultanate of Oman, $1410 \mathrm{AH}$.

3. Ibadi in the procession of history, Ali Yahya Muammar, the Arab Book House, Cairo - Egypt, 1384 AH.

4. Abu Ubaidah Muslim bin Abi Karima al-Ibadi between ignorance and the Imamate, the scientific journal of the College of Fundamentals of Religion and Da wah in Zagazig, No. (21), 2008-2009.

5. Events and attributes, Abu Al-Muathir Al-Salt bin Khamis Al-Kharousi (after 305 AH), investigation: Dr. Jassim Yassin Muhammad Al-Darwish, 1st Edition, Ministry of National Heritage and Culture, Sultanate of Oman

6. Eliminating the objection from Mohaqi Al-Ibad, Muhammad bin Yusef Atfish (d. $1385 \mathrm{AH})$, Ministry of Heritage and Culture, Sultanate of Oman, 1982

7. Removing the disbelief for the followers of Abu al-Sha tha, Salem bin Hamoud alSiyabi (d. 1412 AH), investigation: Dr. Mrs. Ismail Al-Kashef, Ministry of National Heritage and Culture, Sultanate of Oman, 1979.

8. Al-Alam, Khair Al-Din Al-Zarkali, 15th Edition, Dar Al-Alam for Millions, BeirutLebanon, 2002.

9. Al-Amaly, Abu Ja far Muhammad bin Ali bin Babawi al-Qummi, known as Sheikh al-Saduq (381 AH), investigation: Islamic Studies Department at the Mission Institute in Qom, 1st Edition, the Center for Printing and Publishing at the Mission Foundation, $1417 \mathrm{AH}$.

10. Imam Jaber bin Zaid al-Omani, d. Saleh bin Ahmed Al-Sawafi, 2nd edition, Ministry of National Heritage and Culture, Sultanate of Oman, 1409 AH.

11. Research in Boredom and Bees, Jafar Al-Sabhani, 1st edition, The Imam Al-Sadiq (peace be upon him) Foundation, Qom Al-Maqdisah, Iran, 1427 AH.

12. The Beginning of Islam and the Laws of Religion, Lawab Bin Salam, Al-Mazati Al-Ibadi Al-Abadi (d. 273 AH), investigation: Werner Schwartz and Sheikh Salem bin Yaqoub, Dar Sader Printing and Publishing, Beirut-Lebanon, 1986 AD.

13. The crown of the bride on the dictionary jewels, Abu al-Fayd Muhammad ibn Muhammad ibn Muhammad ibn Abd al-Razzaq al-Husayn al-Zubaydi (d. 1205 AH), Dar al-Fikr, Beirut-Lebanon, $1414 \mathrm{AH}$.

14. History of the Apostles and Kings (History of the Tabari), Muhammad bin Jarir bin Yazid al-Tabari (310 AH), 2nd Edition, Dar Al-Turath, Beirut-Lebanon, 1387 $\mathrm{AH}$.

15. Interpretation of the Book of God Almighty, Houd Bin Mahkem Al-Hawari (before $3 \mathrm{AH}$ ), investigation: Al-Hajj Bin Saeed Sharifi, 1st Edition, Islamic Dar AlGharb, Beirut-Lebanon, 1990 AD.

16. Dressing the devil, Jamal al-Din Abu al-Faraj Abd al-Rahman ibn Ali ibn Muhammad ibn al-Jawzi (d. 597 AH), 1st Edition, Dar al-Qalam, Beirut-Lebanon, $1403 \mathrm{AH}$. 


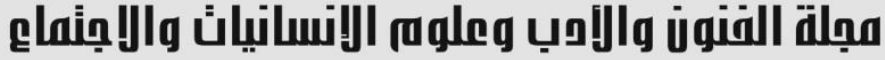 \\ Journal of Arts, Literature, Humanities and Social Sciences www.jalhss.com}

17. Paving the rules of faith, Saeed bin Khalfan Al-Khalili, 1st edition, Sheikh Muhammad Bin Shams Al-Batashi Library for Publishing and Distribution, Muscat Sultanate of Oman, 1431 AH-2010AD.

18. Al-Anbiya Al-Anbiya, Al-Huda Abu Al-Qasim Al-Sayyid Ali bin Hussein bin Musa known as Al-Sharif Al-Murtada is Morteza Alam Al-Hadi (436 AH), 2nd Edition, Dar Al-Adwaa, Beirut-Lebanon, 1409AH-1989AD.

19. Refinement of judgments, Abu Ja`far Muhammad ibn al-Hasan ibn Ali ibn alHasan al-Tusi (460 AH), investigation: Mr. Hassan al-Musawi al-Khursan, 3rd Edition, Islamic Books House, Tehran-Iran, 1364 AH.

20. Facilitating interpretation, Sheikh Muhammad bin Yusuf Atfish (d. 1332 AH), investigation: Sheikh Ibrahim bin Muhammad Talay, 1st edition, Ministry of Heritage and Culture, Sultanate of Oman, 1425AH-2004AD

21. Selected jewels in completing the violation of the Book of Classes, Abu al-Qasim Ibn Ibrahim Al-Brady Al-Damari. (Neighborhood in $810 \mathrm{AH}$ ), investigation: Ahmed bin Saud Al-Siyabi, 1st edition, Dar Al-Hikma, London, 2014.

22. Truth and metaphor in the history of Ibadi in Yemen and the Hejaz, Salem bin Hamoud bin Shams al-Siyabi, Ministry of National Heritage and Culture, Sultanate of Oman, 1440 AH-1980 AD.

23. The Maqrizi plans, Abu al-Abbas Ahmad bin Ali bin Abdul Qadir, al-Husayni alUbaidi, Taqi al-Din al-Maqrizi (d. 845 AH), Dar Sader, Beirut-Lebanon, (D.T.).

24. The Kharijites and the Absent Truth, Nasser bin Suleiman bin Saeed Al-Sabei, Dar Al-Muntadar, Beirut-Lebanon, 1420 AH-2000 CE

25. Advocate, The Good Word, The Scientific Biography of Sheikh Al-Ulamah Ahmed bin Hamad bin Sulaiman Al-Khalili, Grand Mufti of the Sultanate of Oman, Sultan bin Mubarak Al-Shaibani, 1st Edition, Memory of Oman, Muscat-Sultanate of Oman, 1436AH-2015AD.

26. The know-how, the treasure of singing, the end of purpose, and the attainment of sufficiency in the interpretation of five hundred verses, Abu al-Hawari Muhammad bin Al-Hawari Omani Ibadi (d. 278 AH), investigation: d. Muhammad Muhammad Zanati Abdul Rahman, 1st edition, Al-Istikama Library, Sultanate of Oman, 1411 AH1991AD.

27. The Evidence and Proof of the People of Minds to Baghi al-Sabeel with the Light of Evidence for the Realization of the Doctrine of the Right to Evidence and Truth, Abu Yaqoub Yusef bin Ibrahim bin Manad al-Sidrati al-Wajrani (d. 570 AH), investigation: Sheikh Salem bin Hamad al-Harithi, 2nd edition, Ministry of National Heritage and Culture, Sultanate of Oman, 1417AH-1997AD.

28. Rijal al-Tusi, Abu Ja`far Muhammad ibn al-Hasan ibn Ali ibn al-Hasan al-Tusi (460 AH), investigation: Jawad al-Qayumi al-Isfahani, 5th edition, Islamic Publication Foundation of the Fourth Group of Teachers in the Holy Qom, Holy Qom - Iran, $1430 \mathrm{AH}$.

29. A healing message on some dates, Sheikh Muhammad ibn Yusef Atfish (d. 1332 AH), lithograph, Algeria, 1299 AH

30. Gold chains in the origins, branches and literature, Muhammad bin Shams AlBatashi, Ministry of National Heritage and Culture, Sultanate of Oman, (D.T.). 


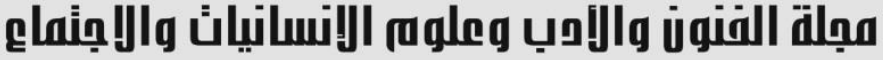 \\ Journal of Arts, Literature, Humanities and Social Sciences www.jalhss.com \\ Volume (53) June 2020 \\ العدد (53) يونيو 2020}

31. A series of weak and placed hadiths and their negative impact on the Ummah, Abu Abdul Rahman Muhammad Nasir al-Din al-Albani (d. 1420 AH), 1st Edition, Dar Al-Maarif, Riyadh-Saudi Arabia, 1412 AH-1992 CE.

32. Sunan al-Tirmidhi, Muhammad bin Isa bin Soora al-Tirmidhi (d. 279 AH), investigation: Bashar Awad Maarouf, Islamic House of the West, Beirut - Lebanon, 1998 AD.

33. Sunan Al-Nasa'i, Abu Abdul-Rahman Ahmad bin Shuaib bin Ali Al-Nasa'i (d. $303 \mathrm{AH}$ ), investigation: Abdel-Fattah Abu Ghadah, 2nd edition, Islamic Publications Office, Aleppo - Syria, 1406 AH - 1986 AD.

34. The conduct of the flags of nobles, Shams al-Din Muhammad bin Ahmed bin Othman al-Dhahabi (d. 748 AH), investigation: Bashar Awad Maarouf, 11th edition, Al-Resala Foundation, Beirut-Lebanon, 1417AH-1996AD.

35. Sirs and answers, scholars and imams of Oman, investigation: d. Mrs. Ismail Kashif, Ministry of National Heritage and Culture, Sultanate of Oman, 1406 AH-1986 AD.

36. Sir, Ahmed bin Saeed bin Abdul Wahid al-Shammakhi (d. 928 AH), investigation: Ahmed bin Saud Al-Siyabi, 2nd edition, Ministry of National Heritage and Culture, Sultanate of Oman, 1412AH-1992AD.

37. Explanation of the Tahawid doctrine, Ali bin Ali bin Muhammad bin Ibn Abi alIzz al-Dimashqi al-Hanafi (d. 793 AH), investigation: Abdullah bin Abdul Mohsen Al-Turki and Shuaib Al-Arnaout, 2nd edition, Al-Resala Foundation, Beirut-Lebanon, 1411AH-1990AD.

38. Explanation of the approach to rhetoric, Izz al-Din, Abu Hamid Abd al-Hamid bin Heba Allah, known as Ibn Abi al-Hadid al-Mu'tazili (d. $656 \mathrm{AH}$ ), investigation: Muhammad Abu al-Fadl Ibrahim, 1st edition, Arab Books Revival House - Issa alBabi al-Halabi and Co., Beirut-Lebanon, 1378 AH-1959 CE.

39. Sahih Al-Bukhari, Abu Abdullah Muhammad bin Ismail Al-Bukhari (d. $256 \mathrm{AH}$ ), Dar Al-Fikr for Printing and Publishing, Beirut-Lebanon, 1401 AH.

40. Sahih Muslim, Muslim ibn al-Hajjaj ibn Muslim al-Qushairi al-Nisaburi (d. 261 $\mathrm{AH}$ ), investigation: Muhammad Fouad Abd al-Baqi, head of the departments of scientific research, advisory, advocacy, and guidance, Riyadh-Saudi Arabia, 1400 AH.

41. Layers of Mashaykh in Morocco (Tabaqat al-Darajini), Abu al-Abbas Ahmad bin Said al-Darajini (d. 670 AH), investigation: Ibrahim Talay, 1st edition, 1394 AH-1974 AD.

42. Silver contracts in the origins of Ibadi, Salem bin Hamad bin Sulaiman Al-Harthi, Ministry of National Heritage and Culture, Sultanate of Oman, 1403 AH-1983 AD.

43. Oman History Speaks, Muhammad bin Ibrahim Al-Salmi, Imam Al-Salmi Library, Sultanate of Oman, (D.T.).

44. The raids, Ibrahim bin Muhammad al-Thaqafi al-Kufi (d. $896 \mathrm{AH}$ ), investigation: Al-Sayyid Jalal al-Din al-Husayni al-Armawi, the modernist, Bahman Press, (D.T) 45. Islamic groups in North Africa, Alfred Bell, translation: Abd al-Rahman Badawi, 3rd edition, Dar al-Gharb al-Islami, Beirut-Lebanon, 1987 AD. 


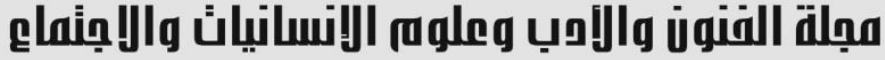 \\ Journal of Arts, Literature, Humanities and Social Sciences www.jalhss.com}

Volume (53) June 2020

العدد (53) يونيو 2020

46. The difference between the teams, Abu Mansour Abd al-Qaher bin Tahir bin Muhammad al-Baghdadi al-Tamimi al-Asfara'ini (d. 439 AH), investigation: Muhammad Uthman al-Khasht, Ibn Sina Library, Cairo.

47. Chapter on boredom, whims and bees, Abu Muhammad Ali bin Ahmed bin Saeed bin Hazm al-Dhahiri (d. 456 AH), Dar Al-Maarefa, Beirut-Lebanon, 1395 AH.

48. Political thought when Ibadi and Zaidi, d. Salem bin Hilal al-Kharusi, 1st Edition, Madbouly Library, Cairo-Egypt, 2006 AD.

49. In the Rehab of the Qur'an (abbreviated interpretation of the scholar Sheikh Bayoud), Sheikh Ibrahim bin Omar Bayoud (d. 1401 AH), summarized by: Sheikh Nasser bin Muhammad Al-Marmouri, 1st edition, Ministry of National Heritage and Culture, Sultanate of Oman, 1428AH-2007AD.

50. The Dictionary of Men, Grand Ayatollah Sheikh Muhammad Taqi Al-Tastari, investigation: The Islamic Publishing Foundation, affiliated to the Teachers 'Group at the Top of the Supervisor, 2nd edition, the Islamic Publishing Institution, affiliated to the Teachers' Group, the Honorable Qom, 1428 AH

51. The Fiqh Dictionary, Language and Terminology, Saadi Abu Jib, 2nd Edition, Dar Al-Fikr, Damascus-Syria, 1408AH-1988AD.

52. Al-Kamil in Language and Literature, Abu Al-Abbas Muhammad bin Yazid AlMubarrad (d. 285 AH), Al-Maaref Library, Beirut - Lebanon, (D.T.).

53. Disclosure of the total cloudiness of the nation's news, Sarhan bin Saeed AlAzkawi (BC 11 AH), investigation: Dr. Muhammad Habib Saleh and d. Mahmoud bin Mubarak Al-Sulaimi, 2nd edition, Ministry of National Heritage and Culture, Sultanate of Oman, 1434AH-2013AD.

54. Detection of anguish, Sheikh Muhammad bin Yusuf Atfish (d. 1332 AH), Ministry of National Heritage and Culture, Sultanate of Oman, 1405 AH-1985AD.

55. Disclosure and statement, Abu Abdullah Muhammad bin Saeed Al-Azdi AlQalhati (d. $4 \mathrm{AH}$ ), investigation: d. Mrs. Ismail Kashif, Ministry of National Heritage and Culture, Sultanate of Oman, 1400 AH-1980 AD.

56. Al-Irfan Treasure in Fiqh of the Qur'an, Jamal al-Din al-Miqdad bin Abdullah alSyouri (d. $826 \mathrm{AH}$ ), edited and directed by: Muhammad Baqir al-Bahbudi, AlMurtadha Library for the Revival of Ja'fari Archeology, $1384 \mathrm{AH}$.

57. Treasure of workers, Aladdin Ali bin Hossam Al-Din Ibn Qazi Khan Al-Qadri Khan Al-Shazly Al-Hendi Al-Burhanfori and then Al-Madani Valki famous for the Indian Mottaki (975 AH).

58. Pathological glow Ibadi rays, Nur al-Din al-Salmi, 1st Edition, memory of Oman, Sultanate of Oman, 1435 AH-2014 AD.

59. Al-Zawadid Complex, Shihab al-Din Abu al-Abbas Ahmad bin Muhammad bin Muhammad bin Ali bin Hajar al-Hitmi al-Sa'di al-Ansari al-Shafi'i (973 AH), Dar alKitab al-'Alami, Beirut-Lebanon, 1408 AH-1988 CE.

60. An introduction to the study of the Ibadites and its faith, Pierre Copperley, translation: Ammar Al-Jalasi, 1st Edition, Dar Al-Farqad, Damascus-Syria, 2011.

61. Reasonable means, Mirza Hussein bin Muhammad Taqi bin Ali Muhammad bin Taqi al-Nuri al-Tabarsi (1320 AH), investigation: Aal al-Bayt (peace be upon him) 


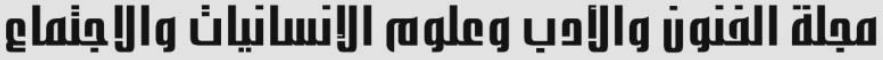 \\ Journal of Arts, Literature, Humanities and Social Sciences www.jalhss.com \\ Volume (53) June 2020 \\ العدد (53) يونيو 2020}

Foundation for the Revival of Heritage, 1st edition, Aal al-Bayt (peace be upon him) Foundation for the Revival of Heritage, Beirut-Lebanon, 1408 AH- 1987 AD.

62. The guide, Abu Ja far Muhammad ibn Jarir ibn Rustum al-Tabari al-Amali (after $410 \mathrm{AH}$ ), investigation: Sheikh Ahmad al-Mahmoudi, 1st Edition, Islamic Culture Foundation, Kushanpur, Qom al-Maqdisah, Iran, 1415 AH.

63. Musnad al-Rabi" printed in the name of the book "Arrangement in the Right" from the hadith of the Messenger (may God bless him and his family), Abu Amr alRabi ibn Habib al-Azdi al-Omani al-Basri (d. 175 AH-180 AH), arranged by: Abu Ya qub Yusef ibn Ibrahim al-Warjalani, corrected and commented on by: Nur ad-Din al-Salmi First Edition, Muscat Library, Sultanate of Oman, 1424AH-2003AD.

64. Mashreq Anwar al-Aqoul, Abu Muhammad Nur al-Din Abdullah bin Humaid alSalmi (d. 1332 AH), Correction and Commentary: Ahmad bin Hamad al-Khalili, investigation: d. Abdul Rahman Amira, 1st Edition, Dar Al-Jeel, Beirut-Lebanon, 1409 AH-1989.

65. The compiler, Abu Bakr Ahmed bin Abdullah bin Musa Al-Kindy (d. 557 AH), Ministry of National Heritage and Culture, Sultanate of Oman, 1403AH-1983AD.

66. Landmarks of Religion, Abdulaziz bin Ibrahim Al-Thumaini Al-Musabi (d. 1220 $\mathrm{AH}$ ), Ministry of National Heritage and Culture, Sultanate of Oman, 1407AH1986AD.

67. Lexicon flags Ibadi, d. Muhammad Salih Nasser, Sultan bin Mubarak AlShaibani, 1st Edition, Islamic Dar Al Gharb, Beirut - Lebanon, 1421AH-2006AD

68. The Maghreb, d. Mr. Abdulaziz Salem, Arab Renaissance House, Beirut Lebanon, 1981.

69. Essays on Islamists, Abu al-Hassan Ali bin Ismail al-Ash'ari (d. $330 \mathrm{AH}$ ), investigation: Muhammad Muhyiddin Abd al-Hamid, 1st edition, the Egyptian Renaissance Library, Cairo-Egypt, 1369 AH-1950 AD.

70. Boredom and bees, Abu al-Fath Muhammad ibn Abd al-Karim al-Shahristani (d. 548 AH), investigation: Muhammad Sayyid Kilani, Mustafa al-Babi al-Halabi and Sons Library, $1378 \mathrm{AH}$.

71. Manners of the Commander of the Faithful Ali bin Abi Talib, Abu al-Hassan Ali bin Muhammad bin Muhammad bin al-Tayyib al-Maliki al-Wasiti al-Maliki known as Ibn al-Maghazali (d. 483 AH), investigation: Abu Abd al-Rahman Turki bin Abdullah al-Wadai'i, 1st Edition, Dar al-Athar, Sana'a-Yemen, 1424 AH-2003 CE.

72. The Summary, Abu Ammar Abd al-Kafi bin Abi Ya`qub Yusef al-Warjalani (d. $570 \mathrm{AH})$, Ministry of Culture, Sultanate of Oman, 2013AD.

73. The emergence of the Ibadi movement, Marwan Khleifat, 1st Edition, Ministry of Heritage and Culture, Muscat - Oman, 1423 AH-2002 AD.

74. Hemian Al-Zad to Dar Al-Maad, Muhammad Bin Youssef Atfish (d. 1385 AH), Ministry of Heritage and Culture, Sultanate of Oman, 1413AH-1993AD. 